\title{
LOS TURISTAS EN EL CENTRO HISTÓRICO DE SALAMANCA: TRÁNSITO, PERCEPCIÓN Y (DES)CONOCIMIENTO
}

\author{
Christelle Cavaillès ${ }^{1}$ \\ Marine Laurent ${ }^{2}$ \\ Simon Maurin ${ }^{3}$ \\ José Luis Sánchez Hernández ${ }^{4}$
}

\section{RESUMEN}

Salamanca se ha convertido en un destino relevante del turismo de interior en España gracias a la política de programación de acontecimientos culturales que se inició en 1993 con la exposición Las Edades del Hombre. Pero los turistas concentran sus itinerarios y visitas en el eje que une la Plaza Mayor con las catedrales y la Universidad a través de la Rúa Mayor. Su percepción de la riqueza patrimonial de la ciudad es, por tanto, muy limitada, como demuestran los resultados del trabajo de campo y de un cuestionario aplicado a los turistas. Este artículo propone medidas para extender la red de recorridos turísticos y enriquecer la experiencia de los turistas que visitan Salamanca.

Palabras clave: turismo; centro histórico; percepción; tránsito; Salamanca.

Tourists in the old city of Salamanca: walking, perception and (mis)awareness

Recibido: 13 de enero de 2015

Devuelto para su revisión: 5 de marzo de 2015

Aceptado: 15 de junio de 2015

1 École primaire publique. Le Bourg. 47600 FRANCESCAS (Francia).E-mail: ch.cavailles@ hotmail.fr

2 ESPE, site de Tarbes, 57 Avenue d'Azerelx, BP 20040. 65950 TARBES CEDEX 9 (Francia). E-mail: marine-zen@hotmail.fr

3 Université Paul Valery. Unité de Formation et de Recherche - Sciences Humaines et Sciences de l'Environnement Bât. Jean-Cocteau - route de Mende. 34199 MONTPELLIER CEDEX 5 (Francia). E-mail: simon.maurin-blaye@outlook.fr

4 Universidad de Salamanca. Departamento de Geografía. Facultad de Geografía e Historia. C/ Cervantes, 3.37071 SALAMANCA (España).E-mail: - jlsh@usal.es 


\begin{abstract}
Salamanca has become an appealing destination in inland Spain due to a successful schedule of cultural events which dates back to 1993, when the exhibition Las Edades del Hombre was launched. However, most of visitors focus their walks and visits to the shaft that connects the Plaza Mayor with the cathedrals and the University along the Rúa Mayor. Their perception of the city's rich heritage is therefore very poor, as the outcomes of fieldwork and a tourist survey clearly suggest. This article proposes some actions to stretch the network of tours and to enrich the experience of tourists who visit Salamanca.
\end{abstract}

Keywords: tourism; historic city; perception; transit; Salamanca.

\title{
1. INTRODUCCIÓN
}

La riqueza patrimonial de las ciudades históricas no se limita a sus monumentos singulares, sean éstos templos, palacios, plazas, murallas o jardines, sino que se nutre de un conjunto mucho más amplio de elementos tangibles e intangibles. Entre los primeros se cuentan, por ejemplo, el emplazamiento topográfico, los edificios de viviendas, los materiales arquitectónicos característicos o el propio plano urbano como herencia palpable de un modo determinado - o de una secuencia histórica de modos - de concebir y construir la ciudad en tiempos pasados. Conceptos como paisaje urbano y morfología urbana permiten aprehender en toda su complejidad esta vertiente visible de la ciudad histórica (De las Rivas y Vázquez, 2011). Entre los segundos, cabe destacar los usos sociales, las actividades económicas y las representaciones culturales que, conjugadas con el sustrato material, definen y reelaboran de continuo la identidad de los centros históricos y su lugar en la imagen y en la percepción colectiva de la ciudad (Millán y Fernández, 2014).

No obstante, el turista que, por su cuenta o en un grupo organizado, visita centros históricos de gran valor, como pueden ser los de ciudades catalogadas por la UNESCO como Patrimonio de la Humanidad, tiende a desarrollar una percepción muy simplificada de esa riqueza entretejida de recursos materiales e inmateriales. Factores inherentes al viaje, como la duración de la estancia, la labor previa de preparación, la búsqueda de información adicional en destino o la posibilidad de hacerse acompañar por familiares o amigos residentes, deben tenerse en cuenta a la hora de comprender y medir la mayor o menor profundidad de la experiencia turística (Donaire y Galí, 2008). Pero también las propias ciudades propician ese proceso de simplificación reduccionista de su patrimonio cuando sus autoridades definen rutas, señalizan itinerarios y distribuyen planos que condicionan en buena medida el desplazamiento de los turistas por el centro histórico y lo dirigen hacia una serie muy limitada de edificios de gran valor icónico y simbólico, cuya contemplación o visita se convierten en una obligación ineludible para todos los visitantes.

Estas prácticas personales e institucionales terminan por construir una imagen muy escueta de los recursos patrimoniales de la ciudad histórica que, por regla general, se compone de una mera sucesión selectiva de fachadas arquitectónicas y perspectivas monumentales que ignora el contexto urbano y social imprescindible para elaborar una 
interpretación más matizada de esos elementos singulares y conferirles un sentido cohesionado y articulado como hitos de la ciudad. Como reconoce Ladwein (2003), la información turística codificada en guías, planos y rutas es indispensable para la organización de los desplazamientos y las estancias, pero estos útiles también limitan la visión de la ciudad a lo pintoresco y lo monumental, imponiendo una determinada representación simplificada o esquemática del laberinto urbano (Escudero, 2013).

Este artículo analiza este problema para el caso de la ciudad de Salamanca, donde se registra una elevadísima concentración de visitantes en el reducido eje Plaza Mayor-Rúa Mayor-Plaza de Anaya/Patio de Escuelas Mayores, mientras otras zonas valiosas del casco histórico y sus aledaños son muy poco transitadas y apreciadas por los turistas. Esta tendencia ya ha sido detectada en ésta y otras ciudades monumentales españolas como Gerona (Galí, 2009), Toledo (Troitiño y otros, 1998), Ávila o Segovia (Troitiño y Troitiño, 2009), pero no se ha avanzado todavía en su representación cartográfica ni en la propuesta de medidas correctoras, tal como pretende este trabajo.

Para alcanzar ambos objetivos, el artículo presenta la siguiente estructura. Tras esta introducción, el segundo apartado sintetiza las aportaciones teóricas y metodológicas sobre el turismo urbano (con especial atención al que se dirige a las ciudades históricas) que mejor pueden ayudar a situar los resultados obtenidos en Salamanca dentro de un contexto de investigación más amplio. El tercer apartado caracteriza brevemente el auge de Salamanca como destino turístico de interior durante el último cuarto de siglo. A continuación se describe la metodología empleada para conocer los itinerarios y representaciones mentales de los turistas en el centro histórico de la ciudad. Los resultados del trabajo de campo y del cuestionario aplicado a estos visitantes se exponen en el apartado quinto y se discuten en relación con los argumentos presentados en el apartado 2. El sexto y último apartado expone una serie de recomendaciones de gestión turística local para corregir la distorsionada percepción que los turistas terminan por adquirir sobre el patrimonio de Salamanca.

\section{LA SIMPLIFICACIÓN DE LA CIUDAD HISTÓRICA: BREVE CONTEXTO TEÓRICO Y METODOLÓGICO}

El problema que plantea este artículo no resulta nuevo en la literatura sobre el turismo urbano. Ashworth y Page (2011) señalan que el turismo que se dirige a las ciudades como destino primordial se caracteriza por su selectividad (visita una parte muy limitada de la ciudad), su rapidez (dedica poco tiempo al destino como tal y a cada uno de los puntos que visita), su volatilidad (está sujeto a modas efímeras que encumbran o relegan determinados destinos) y su baja recurrencia (el regreso es menos probable cuanto más pequeña sea la ciudad).

Esta constatación empírica sustenta las propuestas conceptuales que intentan designar esa realidad parcial y fragmentada en que se ve transformada la ciudad a manos del turismo contemporáneo. Términos como «recinto turístico», «distrito turístico», «enclave turístico»o «burbuja turística» aparecen con frecuencia en los trabajos de Pearce (2001), Judd (2003) o Edwards et al. (2008) para designar zonas pequeñas pero emblemáticas de la ciudad donde se concentran la gran mayoría de los visitantes y se desarrollan lo que García y De la Calle (2008, p.54) califican como «prácticas turísticas altamente ritualizadas», a 
menudo en edificaciones construidas o remodeladas recientemente con ese propósito. Los cascos históricos, principalmente europeos, son quizá la modalidad más acusada y definida de distrito turístico urbano. Así, Ashworth y Tunbridge (2000) han elaborado la noción de «ciudad histórico-turística» para evocar esta transformación de la ciudad histórica en un destino turístico de primer orden, dotado de equipamientos, señalización y elementos de mobiliario urbano distintivos que procuran facilitar el recorrido y la interpretación de los visitantes.

Dentro del extenso campo de investigación sobre el turismo urbano, Edwards et al. (2008) diferencian tres grandes enfoques interrelacionados: el análisis de la industria turística, el estudio de la producción, planificación y gestión del espacio turístico y, por último, la caracterización y comprensión de la experiencia del turista y el consiguiente impacto del turismo sobre la ciudad visitada. La cuestión considerada en este artículo se encuadra, lógicamente, en el tercer enfoque y, según Pearce (2001), figura entre las principales preocupaciones de académicos, gestores y empresarios del sector. No obstante, la identificación de las pautas de desplazamiento de los turistas en la ciudad histórica no sólo tiene un interés intrínseco, sino que debe servir también para orientar la gestión del espacio urbano por parte de las autoridades locales y para informar las decisiones del sector privado en materia de inversión, precios y marketing.

Dicho de otro modo, la retroalimentación continuada entre las aproximaciones económica, política y cultural al análisis del turismo urbano debe ser capaz de generar un conocimiento aplicable y una gestión integrada del fenómeno y del espacio turístico en la ciudad. Solamente así se puede conseguir que la contribución del turismo urbano al desarrollo local sea sostenible en un triple plano económico, social y urbanístico (Ashworth, 2000), evitando caer tanto en el utilitarismo que lo reconoce sobre todo como fuente de ingresos y palanca para la regeneración y revitalización de la ciudad antigua, como en las valoraciones hiper-críticas que cuestionan la conversión de los cascos históricos en parques temáticos o museos al aire libre cuya puntillosa regulación dificulta la evolución y el cambio inherentes a todo espacio urbano (Cócola, 2011).

La investigación sobre el turismo en las ciudades históricas o patrimoniales ha profundizado en estos planteamientos generales con aportaciones que se benefician del detalle que proporciona el análisis local de casos. En una visión sintética sobre el turismo en las ciudades históricas españolas cuya validez aún perdura, De la Calle y García (1998a) se hacen eco de los efectos de la rapidez y la selectividad cuando afirman que estas urbes se enfrentan a dos problemas principales: la excesiva concentración de visitantes en un número muy limitado de recursos y espacios y la consiguiente infrautilización (y desconocimiento) de un vasto conjunto de lugares alternativos cuya puesta en valor enriquecería notablemente «...la idea bastante parcial e incompleta de la ciudad» (p. 261) que adquieren turistas y excursionistas.

El primer problema ha conducido a la definición y aplicación de metodologías para la medición de la capacidad de carga de edificios y conjuntos históricos en Granada, Toledo, León, Sevilla, Carmona o Santiago de Compostela (ver García y De la Calle, 2013, para una revisión minuciosa y reciente) con el objetivo último de regular los flujos de visitantes y evitar el deterioro del recurso. El segundo se ha puesto de manifiesto de manera reiterada en trabajos de conjunto (De la Calle, 2001; García y De la Calle, 2008) 
y en estudios de caso entre los que debe destacarse el de Gerona (Donaire y Galí, 2003; Galí y Donaire; 2006; Donaire y Galí, 2008; Galí, 2009). En el casco antiguo de la capital gerundense se han identificado cuatro itinerarios principales seguidos por los visitantes de la ciudad, de los cuales dos, el llamado básico (ceñido al desplazamiento hasta la Catedral) y el complejo (que añade al itinerario básico la visita a algún otro hito monumental) son practicados por casi el $80 \%$ de los turistas. Estos dos son los itinerarios habituales propuestos por los guías turísticos locales, cuya influencia sobre la práctica turística en la ciudad queda también patente en estos trabajos. El itinerario de las murallas gerundenses es más frecuente entre turistas provistos de una guía impresa o un plano turístico, donde esta opción aparece bien señalizada. La propia concentración de caminantes en una serie muy limitada de calles y edificios de la ciudad constituye un factor orientador de las rutas de los visitantes, al actuar como indicio de la proximidad de un recurso o espacio digno de atención. Este patrón de uso, tan marcado y sostenido, se entiende como herencia de la construcción histórica de la imagen de la ciudad, formalizada en la etapa romántica y transmitido hasta la actualidad sin apenas alteración.

La metodología aplicada para obtener estos resultados se nutre de dos técnicas básicas: la observación directa no participante del tránsito de los turistas y la aplicación de un cuestionario personal a los mismos cuando finalizaban su visita al barrio antiguo de Gerona. A estos instrumentos clásicos de la investigación en materia de turismo urbano (De la Calle y García, 1998b) se han añadido, en los últimos años, otros procedimientos más sofisticados basados en la explotación digital de las imágenes alojadas por los turistas en las redes sociales (Donaire y Galí, 2011, para Barcelona) o en el seguimiento de sus desplazamientos a través de un terminal de GPS proporcionado por el equipo investigador (Bernadó y otros 2012, para el centro histórico de Tarragona). Estas nuevas técnicas de rastreo de la huella digital de los turistas (ver Shoval e Isaacson, 2007, para una síntesis de su potencial para la investigación sobre turismo urbano) no son intrusivas y permiten monitorizar de manera sistemática y en tiempo real el seguimiento de un amplio número de viandantes, aumentando la fiabilidad de los resultados obtenidos.

En este contexto teórico, metodológico y empírico, la investigación presentada en este artículo efectúa tres aportaciones principales. Primera, analiza el caso de Salamanca, una ciudad apenas estudiada de forma monográfica como destino urbano patrimonial; los trabajos disponibles, citados en la bibliografía, la incluyen casi siempre en el conjunto más amplio de las ciudades históricas de Castilla y León o en el de los destinos, por ejemplo, del emergente y lucrativo negocio del turismo idiomático (Pardo, 2011).

Segunda, y derivada de la anterior, se aporta una cartografía de las representaciones mentales manejadas por los turistas que visitan la ciudad histórica de Salamanca, lo que supone un pequeño avance respecto a otros trabajos disponibles sobre ciudades patrimoniales, que dejan constancia del problema de la concentración de los itinerarios sobre unos ejes y nodos muy específicos, pero que no suelen aportar un respaldo cartográfico que facilite la interpretación de los resultados generados mediante las diferentes técnicas aplicadas por los equipos de investigación.

Tercero, y en este punto discrepamos de Ashworth y Page (2011, p. 11) cuando sostienen que «... local authorities have little or no control upon the most important aspects of tourism in their jurisdictions. Critically the number, timing, objectives and spatial 
behaviour of tourists are beyond all but a very marginal influence», se proponen algunas medidas para corregir el patrón actual de distribución del turismo por la ciudad y facilitar a los visitantes una experiencia más completa y variada. Esta vertiente más aplicada del trabajo intentará contribuir a la sostenibilidad del fenómeno turístico en Salamanca, paliando la congestión que afecta a puntos determinados del itinerario estándar y difundiendo los beneficios del flujo turístico hacia otras áreas del casco histórico.

\section{SALAMANCA COMO DESTINO TURÍSTICO EN LA ESPAÑA INTERIOR}

El centro histórico de la ciudad de Salamanca figura en la lista del Patrimonio Mundial de la UNESCO desde 1988. Su «naturaleza ejemplar» (UNESCO, 1988, p.5) procede de la convivencia de cuatro conjuntos principales de recursos: la Plaza Mayor, el complejo de edificios ligados a la Universidad de Salamanca, la arquitectura religioso-conventual (que abarca desde pequeñas iglesias románicas hasta amplios conjuntos renacentistas y barrocos) y la arquitectura civil de palacios nobiliarios reconvertidos hoy a distintos usos públicos o privados, todo ello sin olvidar otros elementos singulares como el puente romano, la modernista casa Lis o el contemporáneo Palacio de Congresos y Exposiciones de Castilla y León, que dilatan en el tiempo la variedad de estilos artísticos representados en la ciudad.

Tales recursos, y los variados usos sociales que se desarrollan en y entre ellos y les dotan de significado en la vida cotidiana de la ciudad, se ubican (salvo el puente sobre el Tormes) en el interior del perímetro de la muralla derribada a finales del XIX (figura 1). De las 130,30 hectáreas rodeadas hoy por la avenida de Mirat, el paseo de Canalejas, el paseo del rector Esperabé, la calle San Gregorio, el paseo de San Vicente y el paseo de Carmelitas, las 50,78 hectáreas inscritas por la UNESCO se han convertido, con el paso del tiempo, en un destino turístico de primera magnitud en el interior de España. Así lo atestigua el hecho de que la ciudad ocupe el séptimo puesto por número de pernoctaciones hoteleras (953.502 en 2013) entre todas las capitales provinciales españolas no litorales, por detrás de ciudades del tamaño y relevancia de Madrid, Sevilla, Granada, Bilbao, Córdoba y Zaragoza, por ese orden, todas ellas mucho más pobladas y con una base económica ciertamente más sólida que les permite beneficiarse también de los viajes relacionados con los negocios y la capitalidad política, en varios casos.

La figura 2 refleja el crecimiento del número de pernoctaciones en Salamanca desde 1999 y muestra, además, que se ha alcanzado una cierta estabilidad en las cifras de los últimos años pese a la crisis económica, lo que confirmaría la consolidación definitiva de la ciudad como destino turístico (Hernández, 2010). El porcentaje de plazas ocupadas corre parejo al de pernoctaciones, señal de que la oferta hotelera ha sido capaz de absorber este flujo de turistas merced a la construcción de nuevos establecimientos y la remodelación de otros ya existentes. A este notable resultado ha contribuido de forma decisiva la programación sucesiva de acontecimientos culturales e institucionales que persiguen el triple objetivo de reforzar la reputación patrimonial de la ciudad, mantener su visibilidad en el tiempo dentro de un mercado turístico cada vez más exigente y competitivo y, por supuesto, alimentar el flujo de visitantes en la misma medida en que ha crecido la oferta de alojamiento y restauración desde comienzos del siglo XXI. 


\section{Figura 1 \\ DELIMITACIÓN DEL ESPACIO DECLARADO PATRIMONIO DE LA HUMANIDAD EN SALAMANCA (SEGÚN LA DEMARCACIÓN DEFINITIVA DE 01/12/2011)}

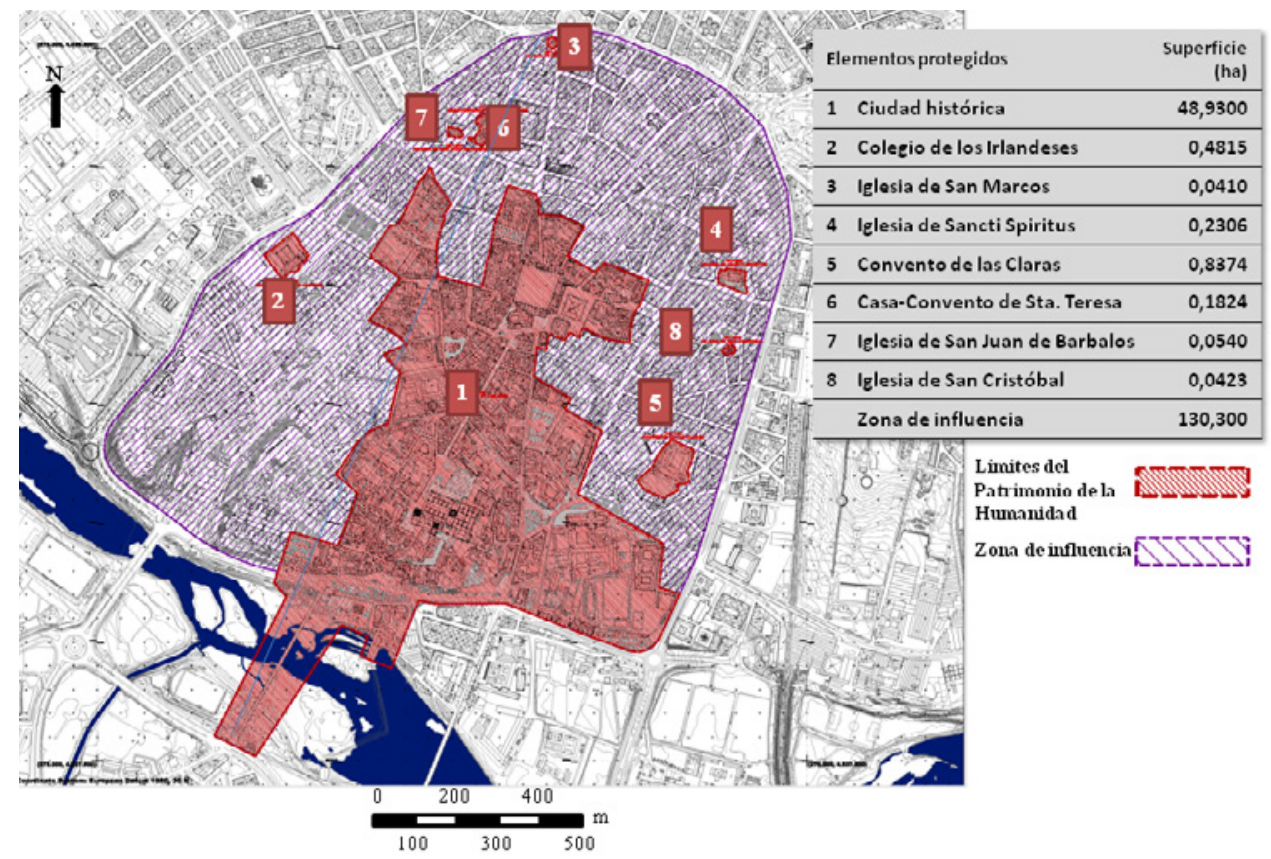

Fuente: adaptado de UNESCO World Heritage Convention-http://whc.unesco.org/download.cfm?id_document= 118626

Existe acuerdo unánime en atribuir a la celebración de la cuarta fase de la exposición Las Edades del Hombre en las catedrales salmantinas (del 3 de diciembre de 1993 al 30 de octubre de 1994) la condición de catalizador inicial de ese esfuerzo colectivo por capitalizar la Declaración de Patrimonio de la Humanidad y colocar a Salamanca en el núcleo del mapa turístico de la España interior (García Zarza, 2002; Troitiño y Troitiño, 2009; Hernández, 2010). Según la web oficial el proyecto Las Edades del Hombre la muestra fue visitada por 1.303.000 personas en los 332 días de apertura (Las Edades del Hombre <en línea>) y generó unos ingresos del orden de los 63 millones de euros (Jiménez y Fernández, 2013). A modo de comparación, puede recordarse que la exposición antológica sobre Velázquez celebrada en el Museo del Prado entre el 23 de enero y el 31 de marzo de 1990 congregó cerca de 600.000 visitantes (Museo del Prado <en línea $>$ ). Un segundo hito relevante en esta trayectoria fue la designación de Salamanca como Capital Europea de la Cultura para el año 2002, condición compartida con la ciudad belga de Brujas. Según el minucioso estudio de Herrero y otros (2006), este acontecimiento reportó a la ciudad cuantiosas inversiones en equipamientos culturales - rehabilitados o de nueva planta- por valor de 46,6 millones de euros, a los que se 
sumaron inversiones privadas en alojamientos hoteleros por un importe acumulado de otros 74,4 millones. Se ha estimado en 1,2 millones de personas la cuantía de asistentes (individuales, descontando las repeticiones) a las actividades programadas, lo que significa unos 368,4 millones de euros de ingresos por venta de entradas.

Figura 2

\section{PERNOCTACIONES HOTELERAS Y PORCENTAJE DE OCUPACIÓN DE PLAZAS HOTELERAS EN LA CIUDAD DE SALAMANCA, 1999-2013}

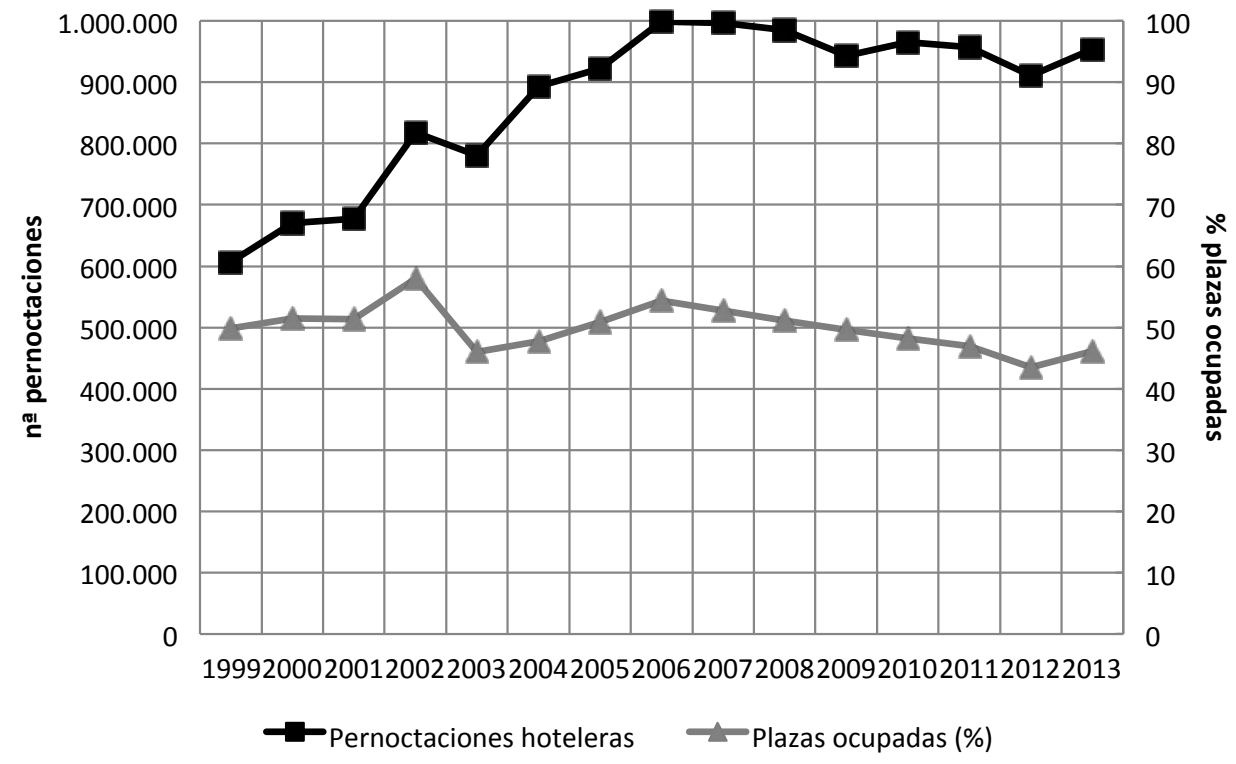

Fuente: elaboración propia con datos de la Encuesta de Ocupación Hotelera (INE).

En conjunto, el citado trabajo estima un impacto económico global de esta Capitalidad Cultural de 701,5 millones de euros, de los que 434 corresponderían a los efectos inducidos en el sector terciario por la programación cultural propiamente dicha y el resto a las inversiones en infraestructuras y equipamientos y su efecto multiplicador sobre el sector de la construcción. A Castilla y León le corresponderían, en concreto, 354,8 millones de euros de impacto en el terciario y 186,9 millones en la construcción. Un resultado relevante de esta investigación es la demostración de que el impacto de los eventos culturales está más concentrado en el territorio (Salamanca y la Comunidad Autónoma de Castilla y León) que el de la inversión en edificaciones (que beneficia también al resto de España y del mundo) y además es mayor en términos absolutos. De ello se deduce la necesidad de sostener una programación cultural y una política de atracción turística continuadas en el tiempo para generar el rendimiento que las dotaciones en capital fijo pueden aportar a la economía urbana y regional; obsérvese, a este respecto, que en 2002 se logró el máximo histórico de ocupación hotelera, según la figura 2. A modo de comparación con otro caso 
de éxito bien conocido y estudiado, los autores apuntan que las cifras de gasto cultural de Salamanca 2002 son superiores a las derivadas del Museo Guggenheim de Bilbao para el mismo año (Herrero y otros 2006, p. 54).

\section{Cuadro 1 \\ EVOLUCIÓN DEL ÍNDICE TURÍSTICO Y LA CUOTA DE MERCADO EN LA CIUDAD DE SALAMANCA, 1986-2012}

\begin{tabular}{|c|r|r|}
\hline Año & \multicolumn{1}{|c|}{$\begin{array}{c}\text { Índice } \\
\text { Turístico }\end{array}$} & $\begin{array}{c}\text { Cuota de } \\
\text { Mercado }\end{array}$ \\
\hline $\mathbf{1 9 8 7}$ & 330 & 504 \\
\hline $\mathbf{1 9 9 3}$ & 345 & 422 \\
\hline $\mathbf{1 9 9 9}$ & 371 & 393 \\
\hline $\mathbf{2 0 0 4}$ & 402 & 372 \\
\hline $\mathbf{2 0 0 6}$ & 405 & 362 \\
\hline $\mathbf{2 0 1 1}$ & 330 & 344 \\
\hline $\mathbf{2 0 1 2}$ & 302 & 342 \\
\hline Saldo 1987-2012(\%) & $-8,48$ & $-32,14$ \\
\hline Saldo 1993-2012(\%) & $-12,46$ & $-18,96$ \\
\hline Saldo 2006-2012 $(\%)$ & $-25,43$ & $-5,52$ \\
\hline
\end{tabular}

Fuente: elaboración propia con datos del Anuario del Mercado Español (BANESTO) y Anuario Económico de España (La Caixa).

La constatación de los buenos resultados de Las Edades del Hombre y la Capitalidad Cultural, tanto en el terreno puramente económico como en la generación de una imagen atractiva de Salamanca, justifica, como se ha dicho, la apuesta por los eventos y conmemoraciones como argumento clave de la estrategia de promoción turística de la ciudad, plasmada en su Plan de Excelencia Turística 2001-2004 que identifica su patrimonio histórico-artístico y su condición de tradicional ciudad universitaria como principales recursos y atractivos locales (Hernández, 2010).

Conseguido en 2003 el reconocimiento de la Semana Santa como Fiesta de Interés Turístico Internacional, a fin de rivalizar con otras ciudades cercanas como Zamora y Valladolid, célebres por su imaginería y sus solemnes desfiles procesionales, se logró después para Salamanca la sede de la XV Cumbre Iberoamericana de Jefes de Estado y de Gobierno en el año 2005, celebrada en su mayoría en edificios pertenecientes a la Universidad de Salamanca, muy vinculada a las universidades hispanoamericanas por

5 No obstante, hay que citar también otras fórmulas para atraer turistas y visitantes: la captación de congresos a través de Salamanca Convention Bureau, su participación en una red de ciudades que se postulan como sede para el rodaje de películas (Salamanca Film Comission), el notable flujo de visitantes que genera la actividad académica regular de la Universidad de Salamanca (Hernández, 2010) y, sobre todo, la promoción de Salamanca como Ciudad del Español (Pardo, 2011). 
lazos históricos e institucionales (Llorente 2004). Tanto este encuentro político como el V Centenario del comienzo de la construcción de la Catedral Nueva (2013) se reflejan en la evolución de la cifra de pernoctaciones (figura 2).

En 2015 se recordó el V Centenario del nacimiento de Santa Teresa de Jesús, cuyo sepulcro se encuentra en la cercana localidad de Alba de Tormes, donde se ha celebrado una nueva edición de Las Edades del Hombre, coordinada en esta ocasión con la catedral de Ávila. Y para el año 2018 está prevista la conmemoración del VIII Centenario de la Universidad de Salamanca, bajo el paraguas del proyecto Horizonte 2018+. La institución ha programado ya diversas actividades culturales y ha conseguido cierta implicación de las administraciones públicas (caso de las exenciones físcales para empresas privadas que patrocinen actividades relacionadas con la efemérides a partir del 1 de noviembre de 2015), pero la premura de tiempo y el contexto de austeridad presupuestaria no invitan al optimismo sobre su capacidad para convertir esta efemérides en un acontecimiento relevante más allá del ámbito académico.

La evolución del índice turístico ratifica esta dependencia que la actividad turística de Salamanca mantiene respecto a los acontecimientos culturales (cuadro 1). Mientras la cuota global de mercado de la ciudad desciende ininterrumpidamente desde 1987 hasta perder un $32 \%$ de su valor inicial en veinticinco años, el índice turístico aumenta de forma sostenida hasta 2004, al amparo de la Capitalidad Cultural y la apertura de nuevos hoteles, para crecer más lentamente hasta 2006, coincidiendo con el máximo absoluto de pernoctaciones hoteleras. En este período, el índice turístico llega a superar a la cuota de mercado, subrayando con claridad la creciente especialización económica de la ciudad en la función turística. Los datos del Observatorio Turístico de Salamanca citados por Hernández (2010, pág. 112) cifran en 230 millones de euros el gasto registrado en la ciudad por los turistas que la visitan y cuya estancia media se estima en 2,8 días. No obstante, el impacto de la crisis económica y la consiguiente dificultad para programar eventos de gran magnitud se dejan sentir con severidad, y el índice se reduce en un 25\% entre 2006 y 2012, hasta quedar de nuevo por debajo de una cuota de mercado ya de por sí menguada y declinante. Dado que las cifras de pernoctaciones y ocupación se mantienen o retroceden muy poco durante este período más reciente, cabe explicar la caída del índice turístico por la reducción de la oferta en términos de número total de habitaciones y también por la bajada de las tarifas que aplican los hoteles a fin de captar más huéspedes, aún a costa de reducir sus márgenes de beneficio.

\section{METODOLOGÍA}

Para conocer las prácticas e itinerarios de los visitantes y turistas que llegan a Salamanca se han utilizado procedimientos diferentes, pero complementarios, siguiendo el principio de triangulación que recomienda Yeung (2003) para la obtención de resultados concluyentes en el campo de la Geografía Económica.

En primer término, la observación de campo en el centro histórico de Salamanca, donde resulta sencillo identificar los monumentos, plazas y calles más transitadas por los turistas, tanto los que se desplazan por su cuenta como los que integran grupos organiza- 
dos dirigidos por guías propios o locales. El hecho de que el centro de trabajo y estudio de los autores de este artículo se ubique dentro del recinto turístico analizado enriquece la observación de campo diseñada ex profeso con la propia experiencia acumulada como transeúntes habituales que, además de los edificios emblemáticos, tenemos un conocimiento directo de las oportunidades que ofrece el centro histórico de Salamanca más allá de los circuitos convencionales.

En segundo lugar, la aplicación de un cuestionario de quince preguntas a cuarenta y ocho turistas ${ }^{6}$ elegidos al azar en diferentes puntos del casco histórico (Plaza Mayor, Catedral, Universidad, Casa de las Conchas, Puente Romano, Rúa Mayor). Además de pedirles unos pocos datos personales (edad, nacionalidad y ocupación), se les preguntó por la modalidad de su viaje (individual o en grupo), los motivos de su visita, la duración de su estancia, el procedimiento seguido para establecer su itinerario en la ciudad, su valoración de la señalización turística y el tipo de tiendas visitadas. También se les propuso mencionar lugares atractivos de la ciudad que no habían podido visitar o que no se recomiendan en la información que han consultado. Por último, se les mostraba un plano de la ciudad para que ubicaran su alojamiento y rodearan los puntos y los itinerarios visitados/recorridos o que tenían intención de visitar/recorrer. Las respuestas cuantificables se tabularon y trataron por procedimientos estadísticos, mientras que los planos se utilizaron como fuente para elaborar mapas mentales de la ciudad en función de la duración del viaje de los turistas (ver figuras 3 a 6), apreciándose diferencias notables que se discutirán en el apartado siguiente.

En tercer lugar, y a fin de perfilar y comprobar la validez de los resultados del cuestionario, se concertaron entrevistas con distintos actores del sector turístico y visitas a los principales centros de información turística. Se pidió, de manera informal, a cuatro turistas (español que viaja de manera independiente, español que viaja en grupo, extranjero que viaja de manera independiente y extranjero que viaja en grupo) que relataran cronológicamente su estancia y desplazamientos en Salamanca. Se planteó también una entrevista semiestructurada con una guía turística, a la que se preguntó por los itinerarios que propone a los grupos y las modulaciones que introduce en función del número y procedencia de los integrantes, por los requerimientos de información que le plantean los turistas y por su propia valoración sobre la calidad de la señalización turística y de la información impresa que se proporciona a los visitantes. Así mismo, se redactó un cuestionario dirigido a la gerencia de la Oficina Municipal de Turismo de Salamanca, situada en la Plaza Mayor, pero no se recibió respuesta a las llamadas telefónicas ni a los correos electrónicos que se enviaron solicitando información. Algunos autores de este artículo se hicieron pasar por turistas y visitaron dicha Oficina para solicitar consejo para visitar Salamanca en un día. Por último, se visitó el centro de interpretación del patrimonio «Monumenta Salmanticae» (Monumenta Salmanticae <en línea>) concebido

6 El reducido tamaño de la muestra limitaría la validez estadística de los resultados en caso de utilizarse esta técnica como única fuente de datos para el posterior análisis del fenómeno estudiado. Sin embargo, en virtud del método de la triangulación, que combina información procedente de distintas fuentes, y, muy en particular, de la experiencia y observación de campo, consideramos que los resultados obtenidos (sobre todo, los mapas mentales) no se ven afectados en lo fundamental por esta cuestión, que acertadamente han planteado los evaluadores del artículo, 
para acoger a los turistas y ofrecerles, mediante la proyección de un audiovisual, una imagen de conjunto del patrimonio de la ciudad que sirva de orientación para la posterior visita individual o en grupo.

Naturalmente, las fuentes documentales (planos de la ciudad, sitios en Internet) fueron también objeto de análisis para cotejar sus contenidos con la información recabada mediante la observación de campo, las entrevistas y cuestionarios.

Como se ha puesto de manifiesto en el apartado 2, hay otras técnicas digitales más complejas para estudiar el comportamiento espacial y temporal de los turistas y visitantes de la ciudad histórica. En esta investigación se han empleado únicamente los medios ya citados puesto que no se contaba con financiación específica ninguna y el plazo disponible para el desarrollo del trabajo de campo se limitaba a un cuatrimestre dentro del calendario de actividades docentes.

\section{RESULTADOS Y DISCUSIÓN}

\subsection{Perfil de los turistas y su estancia en Salamanca}

Los rasgos básicos de los turistas encuestados muestran una amplia mayoría de mujeres y una concentración entre los grupos de edad comprendidos entre los 40 y los 80 años (cuadro 2). Se trata de personas jubiladas en un 39,5\%, mientras estudiantes y ocupados se reparten el resto de la muestra en porcentajes muy semejantes; como parece lógico, no hay personas desempleadas entre los entrevistados. El 60,4\% de los entrevistados han llegado a Salamanca por su propia cuenta y el resto forman parte de un grupo o viaje organizado. La estancia es mayoritariamente breve, con un $77 \%$ de visitantes que permanecen en la ciudad tres días o menos. Este dato es congruente con los 2,8 días de estancia media que señala Hernández (2010) con datos del Observatorio Turístico de Salamanca (ver apartado 2).

Los motivos que los mueven a visitar Salamanca son variados, si bien debe subrayarse el hecho de que los monumentos concretos reciben muy pocas menciones, pese a su pretendida fama universal, mientras que la ciudad como tal sí que parece constituir un destino atractivo en su conjunto, quizá como resultado del diseño de un producto Salamanca por parte de la empresa pública Turismo de Salamanca, responsable del marketing turístico local.

De hecho, hay cinco menciones de personas que regresan a una ciudad que ya conocían (lo que parece confirmar la baja recurrencia que citan Ashworth y Page, 2011), y otras cuatro que aducen la visita familiar como motivo de su viaje, pero que aprovechan la ocasión para pasear por los puntos neurálgicos del patrimonio arquitectónico salmantino, que es donde se han efectuado las entrevistas. Durante su visita a Salamanca, los turistas recurren a diferentes fuentes de información para seleccionar su recorrido (cuadro 3). La Oficina Municipal de Turismo y los guías (oficiales de la ciudad o propios de cada grupo) se distinguen como actores principales en este terreno, lo cual tendrá efectos directos sobre los destinos visitados por los turistas, como se demuestra en el epígrafe siguiente, mientras son muy pocos quienes llevan una guía impresa, lo que concuerda con los datos de Galí (2009) para el caso de Gerona. 


\section{Cuadro 2 \\ CARACTERÍSTICAS PRINCIPALES \\ DE LOS TURISTAS ENTREVISTADOS $(\mathrm{N}=48)$}

\begin{tabular}{|c|c|c|c|}
\hline Variable & Categoría & Total & Porcentaje \\
\hline \multirow{2}{*}{ Sexo } & Hombres & 15 & 31,2 \\
\hline & Mujeres & 33 & 68,8 \\
\hline \multirow{6}{*}{ Edad } & $<18$ años & 8 & 16,6 \\
\hline & $18-25$ años & 5 & 10,4 \\
\hline & $25-40$ años & 2 & 4,2 \\
\hline & $40-60$ años & 14 & 29,2 \\
\hline & $60-80$ años & 17 & 35,4 \\
\hline & $>80$ años & 2 & 4,2 \\
\hline \multirow{4}{*}{ Actividad } & Estudiante & 14 & 29,2 \\
\hline & Parado & 0 & - \\
\hline & Ocupado & 15 & 31,3 \\
\hline & Jubilado & 19 & 39,5 \\
\hline \multirow{4}{*}{$\begin{array}{l}\text { Duración de la } \\
\text { estancia }\end{array}$} & Un día & 15 & 31,3 \\
\hline & Dos o tres días & 22 & 45,8 \\
\hline & Cuatro a siete días & 6 & 12,5 \\
\hline & Más de una semana & 5 & 10,4 \\
\hline \multirow{2}{*}{ Modo de visita } & En grupo & 19 & 39,6 \\
\hline & Particular & 29 & 60,4 \\
\hline \multirow{7}{*}{$\begin{array}{l}\text { Motivo de la visita } \\
\text { (respuesta múltiple) }\end{array}$} & Ya conocía la ciudad & 5 & - \\
\hline & Visitar la ciudad & 26 & - \\
\hline & Visitar a la familia & 4 & - \\
\hline & Visitar la Plaza Mayor & 1 & - \\
\hline & Visitar la Universidad & 2 & - \\
\hline & Visitar la Catedral & 2 & - \\
\hline & Otros & 24 & - \\
\hline
\end{tabular}

Fuente: elaboración propia a partir del cuestionario a turistas.

Cuadro 3

PROCEDIMIENTO DE ELECCIÓN DEL ITINERARIO EN SALAMANCA

\begin{tabular}{|l|c|}
\hline Fuente de información & Total \\
\hline Oficina de Turismo & 11 \\
\hline Visita guiada & 14 \\
\hline He comprado una guía turística & 4 \\
\hline Información de la agencia de viajes & 2 \\
\hline Internet & 3 \\
\hline Familia & 4 \\
\hline Ya conocía Salamanca & 9 \\
\hline Camino sin itinerario prefijado & 11 \\
\hline Total & $\mathbf{5 8}$ \\
\hline
\end{tabular}

Fuente: elaboración propia a partir del cuestionario a turistas. 


\subsection{Patrones de desplazamiento de los turistas en el casco histórico de Salamanca: la influencia del tipo de viaje}

Los turistas que acuden a Salamanca en viajes organizados visitan la ciudad principalmente en grupo con guía propio o contratado in situ (50\%). Las restantes opciones son muy minoritarias (cuadro 4), por lo que su conocimiento de la ciudad queda sujeto a las rutas establecidas por estos profesionales. La situación de los viajeros «particulares» (quienes se desplazan por su cuenta) es más plural y no dependen tanto de una sola fórmula para conocer la ciudad; su estancia en Salamanca se rige por ese patrón de mayor autonomía, puesto que sólo el $8 \%$ recurre a la visita guiada, frente al $25 \%$ que se informa en la Oficina de Turismo. En este grupo también se menciona la familia como fuente de información (11\%), lo que a su vez parece consistente con el hecho de que se haya visitado anteriormente la ciudad $(19,4 \%)$ en mucha mayor medida que entre los viajeros en grupo: podría aventurarse la hipótesis de que los viajes colectivos son una primera aproximación elemental a Salamanca y algunos de estos turistas repiten visita después bajo un formato más independiente una vez que adquieren un conocimiento básico de la ciudad.

Incluso así, los visitantes que caminan sin un itinerario prefijado no llegan al $20 \%$ en ninguno de los dos grupos, lo que demuestra con claridad la influencia de las fuentes documentales y orales en la formación de los patrones individuales de desplazamiento por la ciudad.

\section{Cuadro 4}

PROCEDIMIENTO DE ELECCIÓN DEL ITINERARIO SEGÚN LA FORMA DE LLEGADA A SALAMANCA

\begin{tabular}{|l|c|c|}
\hline Fuente de información & Viaje particular & Viaje en grupo \\
\hline Oficina de Turismo & 9 & 2 \\
\hline Visita guiada & 3 & 11 \\
\hline He comprado una guía turística & 2 & 2 \\
\hline Información de la agencia de viajes & 1 & 1 \\
\hline Internet & 3 & - \\
\hline Familia & 4 & - \\
\hline Ya conocía Salamanca & 7 & 2 \\
\hline Camino sin itinerario prefijado & 7 & 4 \\
\hline Total & $\mathbf{3 6}$ & $\mathbf{2 2}$ \\
\hline
\end{tabular}

Fuente: elaboración propia a partir del cuestionario a turistas.

La apreciable diferencia en la forma de desplazarse por Salamanca y conocer su tejido urbano y su patrimonio histórico y artístico se refleja con claridad en las figuras 3 y 4 , que muestran los lugares visitados por los turistas que llegan en grupo y por los que viajan por su cuenta, respectivamente. La figura 3 muestra un patrón de visitas más concentrado en el 
núcleo del eje Norte-Sur que une la Plaza Mayor con las Catedrales y la Universidad, a través de la Rúa Mayor y con parada intermedia obligada en la célebre Casa de las Conchas, donde resulta obligado narrar la leyenda de un tesoro escondido en uno de tales motivos decorativos de la fachada. Parten de este tronco central ramificaciones muy cortas hacia otros tres puntos afamados por distintos motivos: el Palacio de Monterrey, propiedad de la Casa de Alba y, por tanto, del interés de un amplio segmento del público; el Convento de San Esteban, donde Cristóbal Colón debatió con los monjes dominicos sobre la viabilidad de su primer viaje a América; y la Casa Lis, raro ejemplo de arquitectura modernista en Salamanca y museo más visitado de la comunidad autónoma de Castilla y León, a la que resulta muy fácil y rápido acceder desde las Catedrales.

\section{Figura 3 \\ PLANO SINTÉTICO DE LOS LUGARES VISITADOS POR LOS TURISTAS QUE RECORREN SALAMANCA EN GRUPO}

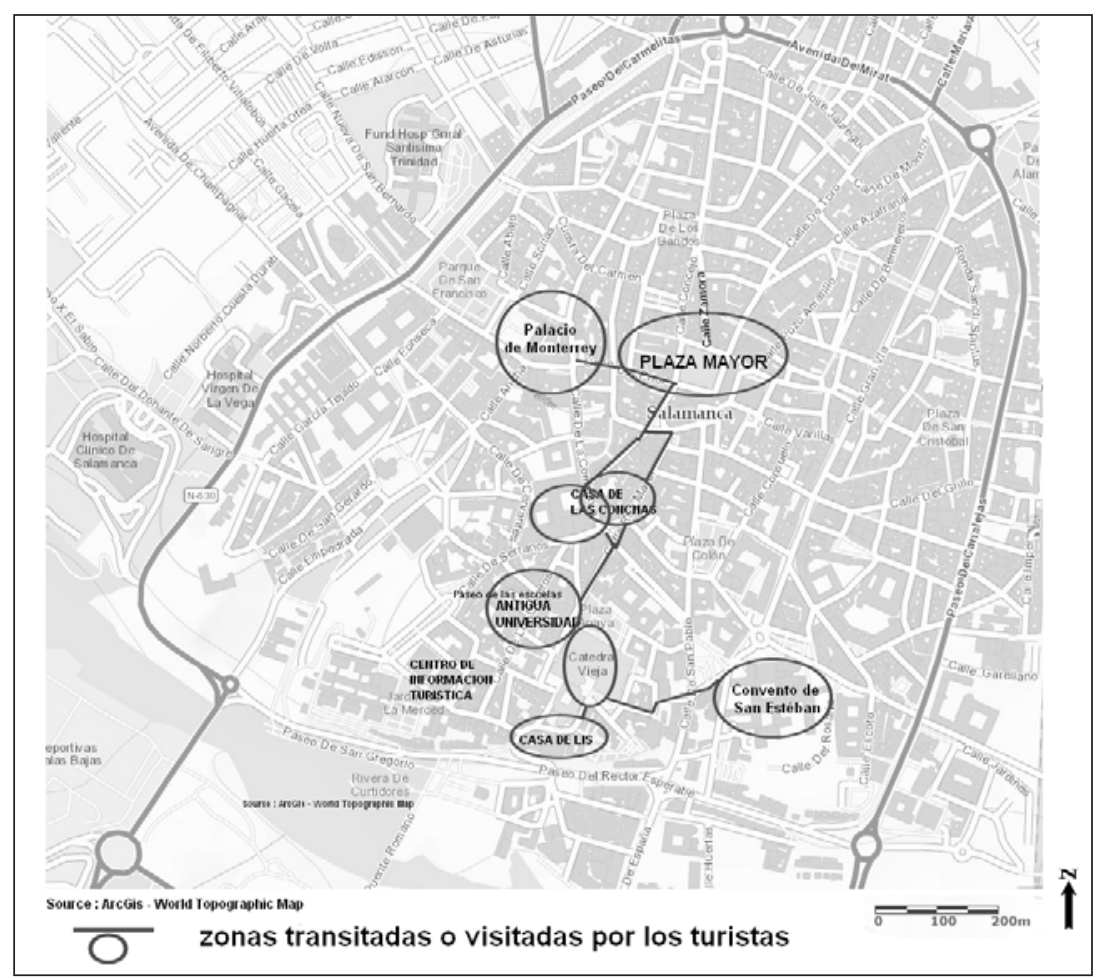

Fuente: elaboración propia a partir del cuestionario a turistas.

El papel orientador de los guías que dirigen estas visitas se aprecia en tres hechos concretos: primero, la reducida longitud del itinerario, comparado con el que muestra la figura 4; segundo, la inclusión de monumentos próximos cuya relevancia artística es indiscutible, pero que se incluyen en el paseo por su relación más o menos directa con la 
cultura popular en detrimento de otros algo más alejados y quizá menos vistosos, como el Puente Romano; tercero, su meritoria contribución a extender el flujo turístico fuera del eje Norte-Sur con estas ramificaciones que, aunque selectivas, diversifican tenuemente el acusado patrón meridiano del tránsito de turistas en Salamanca. En este sentido, conviene recordar que el personal de la Oficina de Turismo no mencionó estos tres monumentos cuando se le solicitó consejo sobre los destinos que deberían visitarse durante una estancia de un día en la ciudad, de modo que las visitas guiadas siguen un planteamiento menos restrictivo que las orientaciones oficiales.

\section{Figura 4 \\ PLANO SINTÉTICO DE LOS LUGARES VISITADOS POR LOS TURISTAS QUE RECORREN SALAMANCA POR SU CUENTA}

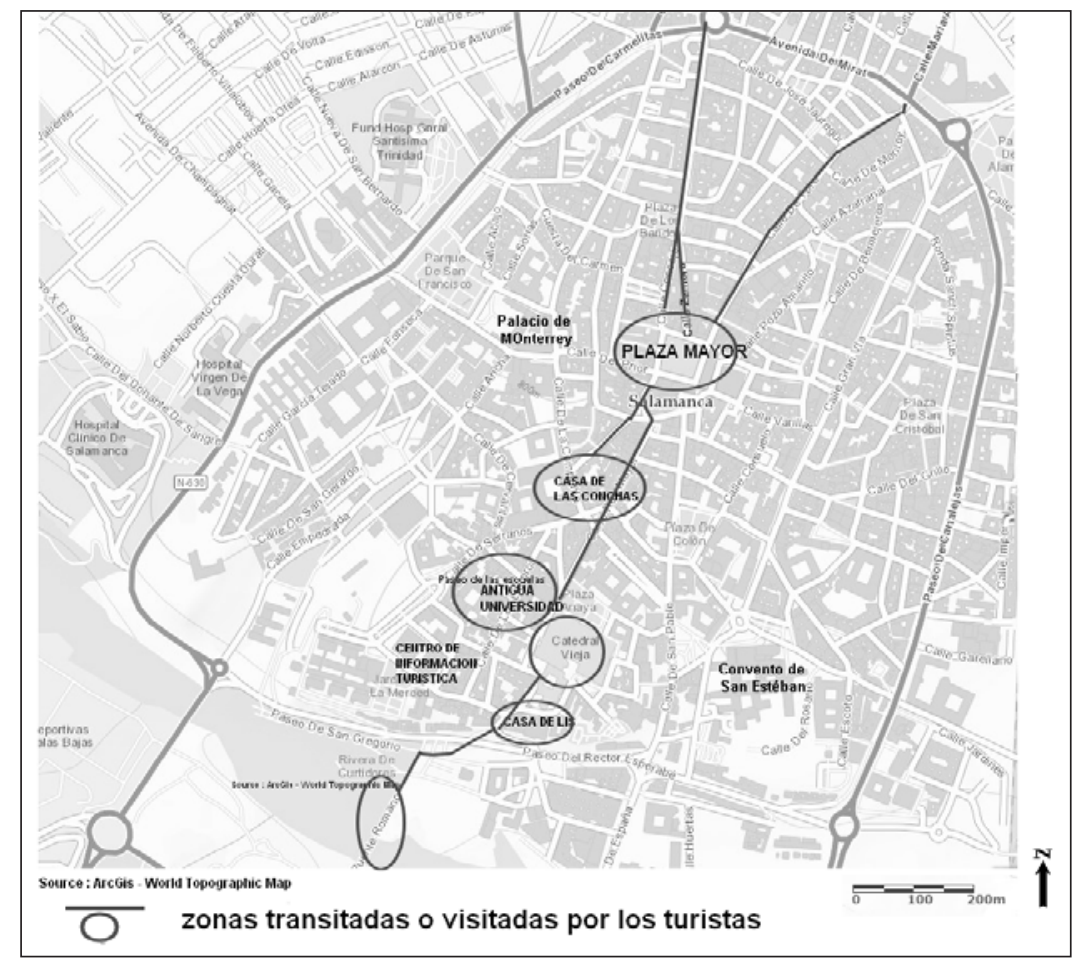

Fuente: elaboración propia a partir del cuestionario a turistas.

A fin de ilustrar esta cuestión, se reproducen a continuación algunos pasajes de la entrevista mantenida con una guía turística que ejerce su profesión en Salamanca: «Las visitas de los turistas, vale, lo más importante es que tienen que entrar por la Plaza Mayor, por supuesto, la Catedral también, también la Casa de las Conchas, y la fachada de la rana ... Después si quieren ampliarlo pues San Esteban, Palacio de Monterrey ... Los turistas sólo escuchan lo que se les explica y no piensan en ver otras cosas ... Tengo 
grupos de varias nacionalidades y edades, cuando empieza la visita están pendientes de lo que cuentas, no están más interesados en otras cosas o lugares. En general les gusta todo lo que ven, y son interesados».

La figura 4, correspondiente a los turistas que llegan a Salamanca en viaje particular, tiene un patrón más rectilíneo en la dirección N-S. Aconsejados por la Oficina de Turismo, por sus familiares o por su experiencia previa, transitan por los ejes principales que convergen en la Plaza Mayor por el Norte: la calle de Zamora los lleva hasta la notable iglesia románica de San Marcos, cuya planta circular es única en la ciudad, mientras la calle de Toro aglutina las firmas y franquicias comerciales más extendidas en España. Por el Sur, la Rúa Mayor se perfila de nuevo como vector principal del tránsito hacia el área de la Universidad y las Catedrales, que se prolonga en este caso también hacia la Casa Lis y el Puente Romano. Escasean, por el contrario, las menciones a edificios como el Palacio de Monterrey y el Convento de San Esteban, ajenos a este itinerario central tan definido entre los visitantes que caminan de forma más espontánea o personal por Salamanca.

Cabe preguntarse por la influencia de la señalización turística en estas pautas de tránsito por la ciudad. Las respuestas a esta pregunta en el cuestionario muestran una distribución prácticamente normal en términos estadísticos (cuadro 5). El 46,6\% de los encuestados hicieron una valoración neutra de la señalización de los monumentos, el $22,4 \%$ la consideran buena, el $24,1 \%$ mala, el 5,2\% muy buena y el $1,7 \%$ muy mala. Estos resultados globales sugieren que la señalización es mejorable, aunque tampoco supone un obstáculo sustancial para la orientación de los turistas en su conjunto. Ahora bien, la segmentación de las respuestas según la forma de elección del itinerario introduce matices sustanciales en esta valoración inicial. Las personas que manifiestan mayor descontento con la señalización son las que caminan por Salamanca sin experiencia previa ni siguen a un guía profesional, sino que consultan planos oficiales o se limitan a pasear por sus calles. En otras palabras, los turistas que deambulan sin ayuda externa (guías, familia, su propio conocimiento previo), parecen encontrar dificultades para orientarse por Salamanca y llegar a los monumentos que desean visitar. El trabajo de campo ha permitido constatar que, en efecto, los carteles identificativos se ubican delante de los distintos monumentos, pero faltan indicaciones claras y frecuentes que conduzcan a esos destinos concretos desde los diferentes puntos de la ciudad. Y la experiencia personal indica que es muy habitual ser preguntado en la calle por visitantes (individuos, familias, pequeños grupos) que desean llegar a los puntos más renombrados (Plaza Mayor, Catedrales, fachada de la Universidad) y se encuentran desorientados a apenas cuarenta o cincuenta metros de su destino.

Los guías turísticos también tienen su posición particular sobre este asunto. Reconocen la escasez de indicadores en las calles, pero no la consideran problemática porque «Salamanca es tan pequeña que si vas a la Oficina de Turismo te enseñan todo lo que tienes que ver... Hay gente que se equivoca y piensa que ésta [la Casa de las Conchas] es la Catedral, pero tampoco es nada grave porque la Catedral está al final de la calle», en palabras de la guía entrevistada. Y ello a pesar de la diferencia detectada en esta investigación sobre las rutas que siguen los turistas que asisten a visitas guiadas y los que caminan por su cuenta. En el apartado final de Recomendaciones se vuelve a tratar este asunto que consideramos tiene más relevancia de la que le atribuyen los guías. 


\section{Cuadro 5 \\ VALORACIÓN DE LA SEÑALIZACIÓN DE LOS MONUMENTOS SEGÚN LA ELECCIÓN DEL ITINERARIO}

\begin{tabular}{|l|c|c|c|c|c|c|}
\hline Fuente de información & Muy mal & Mal & Normal & Bien & Muy bien & Total \\
\hline Oficina de Turismo & 0 & 5 & 3 & 3 & 0 & 11 \\
\hline Visita guiada & 0 & 2 & 7 & 4 & 1 & 14 \\
\hline He comprado una guía turística & 0 & 2 & 1 & 1 & 0 & 4 \\
\hline Información de agencia de viajes & 0 & 0 & 1 & 1 & 0 & 2 \\
\hline Internet & 0 & 0 & 3 & 0 & 0 & 3 \\
\hline Familia & 0 & 0 & 4 & 0 & 0 & 4 \\
\hline Ya conocía Salamanca & 0 & 1 & 6 & 2 & 0 & 9 \\
\hline Camino sin itinerario prefijado & 1 & 4 & 2 & 2 & 2 & 11 \\
\hline Total & $\mathbf{1}$ & $\mathbf{1 4}$ & $\mathbf{2 7}$ & $\mathbf{1 3}$ & $\mathbf{3}$ & $\mathbf{5 8}$ \\
\hline
\end{tabular}

Fuente: elaboración propia a partir del cuestionario a turistas.

\subsection{Los mapas mentales de los turistas según la duración de su estancia en Salamanca}

El apartado anterior ha presentado el resultado agregado de la Salamanca visitada por una muestra de turistas en la que predominan las estancias cortas, de uno a tres días (cuadro 2). Sin embargo, ese resultado varía notablemente cuando se desglosa la información recabada en las entrevistas según la duración de la estancia del interlocutor (figuras 5, 6, 7 y 8).

Los excursionistas, es decir, las personas que no pernoctan en Salamanca y la visitan durante una jornada, adquieren una visión incluso más limitada que la de quienes siguen los pasos de un guía (comparar con la figura 3). Hay que tener en cuenta que estas personas, en general, participan en circuitos turísticos organizados que visitan varias ciudades en días sucesivos, o que vienen de Madrid a pasar el día en Salamanca. Su objetivo no es tanto conocer la ciudad más o menos en detalle como acercarse a los monumentos más conocidos y característicos de la ciudad.

Así, muy pocos se aventuran al norte de la Plaza Mayor, para concentrarse preferentemente a lo largo del eje de la Rúa Mayor, que conduce a las Catedrales y la Universidad, previa parada obligatoria en la Casa de las Conchas. La Rúa Mayor, la calle más especializada de Salamanca en servicios al visitante (por sus tiendas de recuerdos y de alimentos típicos, más sus variados establecimientos de restauración y algunos hoteles y alojamientos), recibe un tratamiento significativo en la información que proporcionan los entrevistados. Cuando se les pide que marquen en un plano los lugares que han visitado o recorrido, señalan la Plaza, la Catedral y, en segundo plano, la Casa de las Conchas, pero, curiosamente, no recuerdan la Clerecía ni la Universidad Pontificia, situadas justo frente a la Casa de las Conchas en una calle estrecha. Ahora bien, cuando se les pregunta por las calles que conocen, todos citan de inmediato la Rúa Mayor. Esto significa que, como 


\section{Figura 5 \\ PLANO SINTÉTICO DE LOS LUGARES VISITADOS POR LOS TURISTAS QUE PERMANECEN EN SALAMANCA POR UN DÍA}

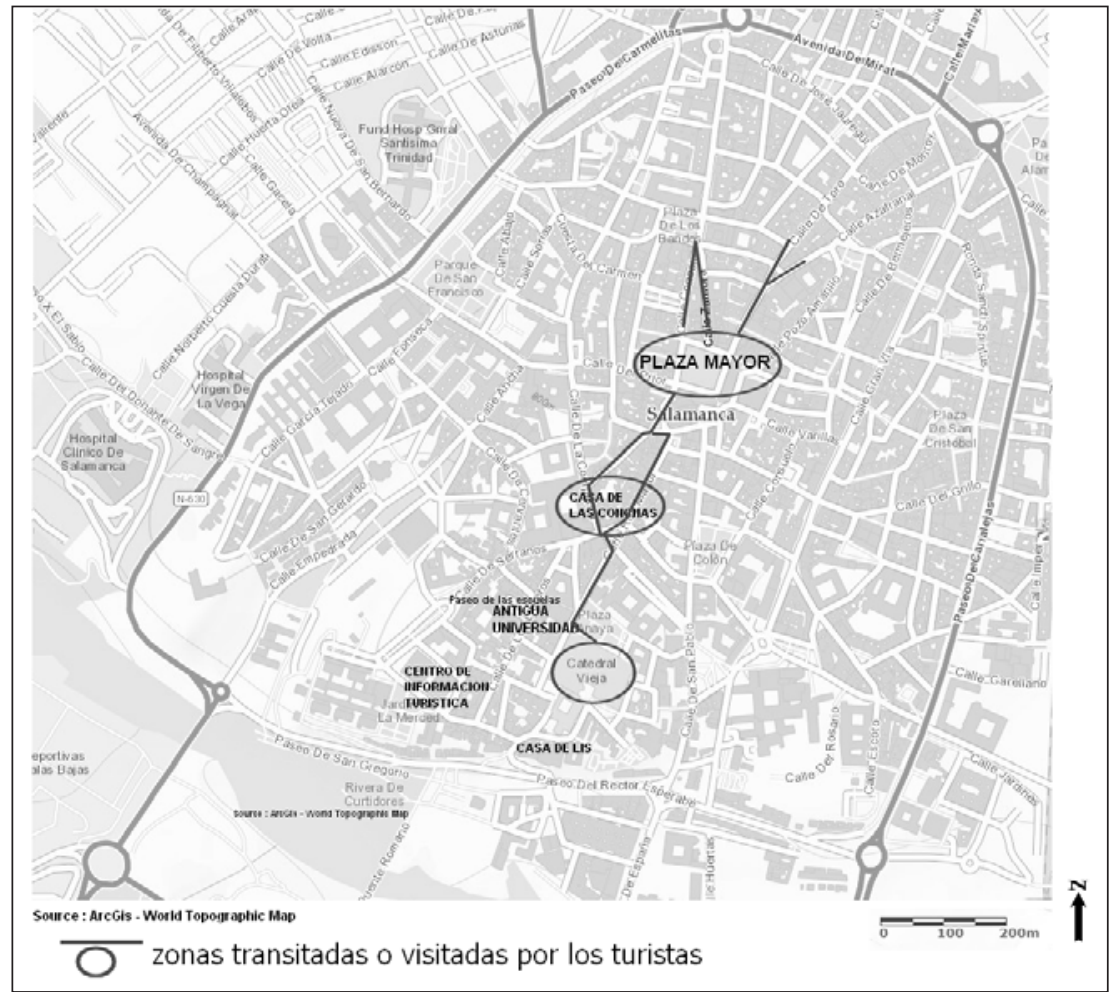

Fuente: elaboración propia a partir del cuestionario a turistas.

se argumentaba en la Introducción, el objetivo de los turistas es ver monumentos y no formarse una imagen más amplia y compleja del paisaje urbano de la ciudad. Por tanto, las calles se ven reducidas a la mera condición de conectores de monumentos, sin cobrar interés ninguno por sí mismas. Como la Rúa Mayor desemboca en la Plaza de Anaya, donde se levanta la Catedral Nueva, el límite meridional de la experiencia del excursionista queda establecido en este lugar.

Quienes permanecen de uno a tres días en Salamanca (figura 6) siguen un patrón de desplazamiento prácticamente idéntico al mostrado en la figura 4 y correspondiente a los turistas que viajan por su propia cuenta. Este es el grupo más numeroso de la muestra (45,8\% del total) y parece lógico que sus respuestas condicionen en gran medida los resultados de conjunto. Respecto al grupo anterior, el de los excursionistas que no pernoctan, estos turistas (de fin de semana, de puentes festivos) presentan un patrón de movilidad más amplio. Las dos arterias comerciales al norte de la Plaza, calles de Toro y de Zamora, aparecen perfectamente definidas, mientras por el sur vuelve a aparecer la Casa Lis y se 


\section{Figura 6 \\ PLANO SINTÉTICO DE LOS LUGARES VISITADOS POR LOS TURISTAS QUE PERMANECEN EN SALAMANCA ENTRE UNO Y TRES DÍAS}

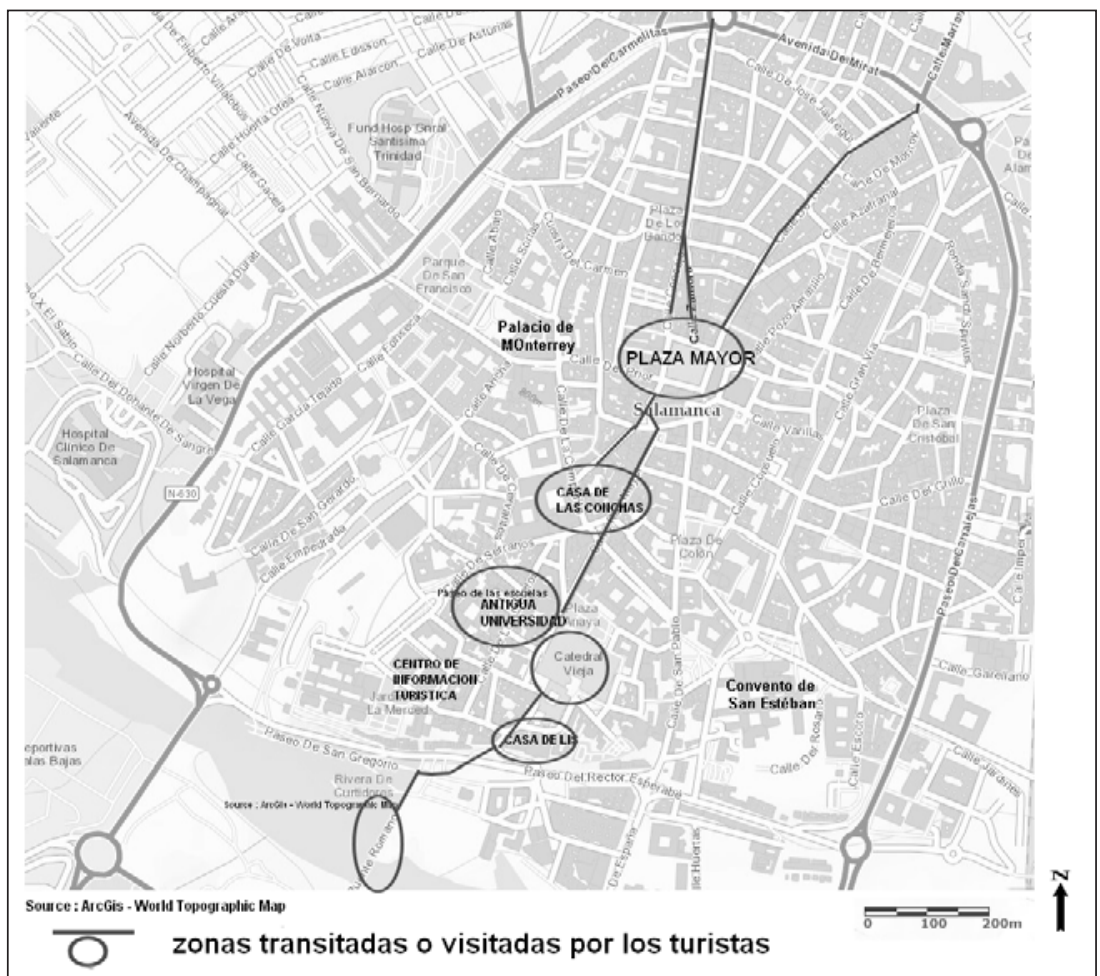

Fuente: Elaboración propia a partir del cuestionario a turistas.

incorpora el Puente Romano a los destinos visitados. No obstante, otros lugares de interés mostrados por los guías, como el Convento de San Esteban y el Palacio de Monterrey, continúan ausentes, lo que no deja de ser sorprendente dada su proximidad al eje central Norte-Sur y las recomendaciones de todas las guías impresas o digitales. En todo caso, los turistas continúan recluidos en el casco histórico y no se aventuran fuera de la ronda de la antigua muralla, bien remarcada en el plano urbano.

La diferencia entre las figuras 6 y 7 es muy pequeña, pues solamente aparece como nuevo destino la calle San Pablo, que conduce a la Plaza de Colón y donde también puede visitarse el Palacio de La Salina, sede de la Diputación Provincial. De este modo, se constata que la disposición en aspa de las calles que parten de la Plaza Mayor (ZamoraSan Pablo y Toro-Rúa) refuerza la centralidad del ágora para el visitante y orienta sus desplazamientos convirtiéndola en hito de referencia viario y simbólico, como sucede con los habitantes de la ciudad. Podría decirse, a tenor de estos resultados, que tres días son suficientes para conocer los monumentos más característicos de Salamanca y que, a partir de ese umbral, el turista no amplía significativamente su marco espacial de referencia. 


\section{Figura 7 \\ PLANO SINTÉTICO DE LOS LUGARES VISITADOS POR LOS TURISTAS QUE PERMANECEN EN SALAMANCA ENTRE CUATRO Y SIETE DÍAS}

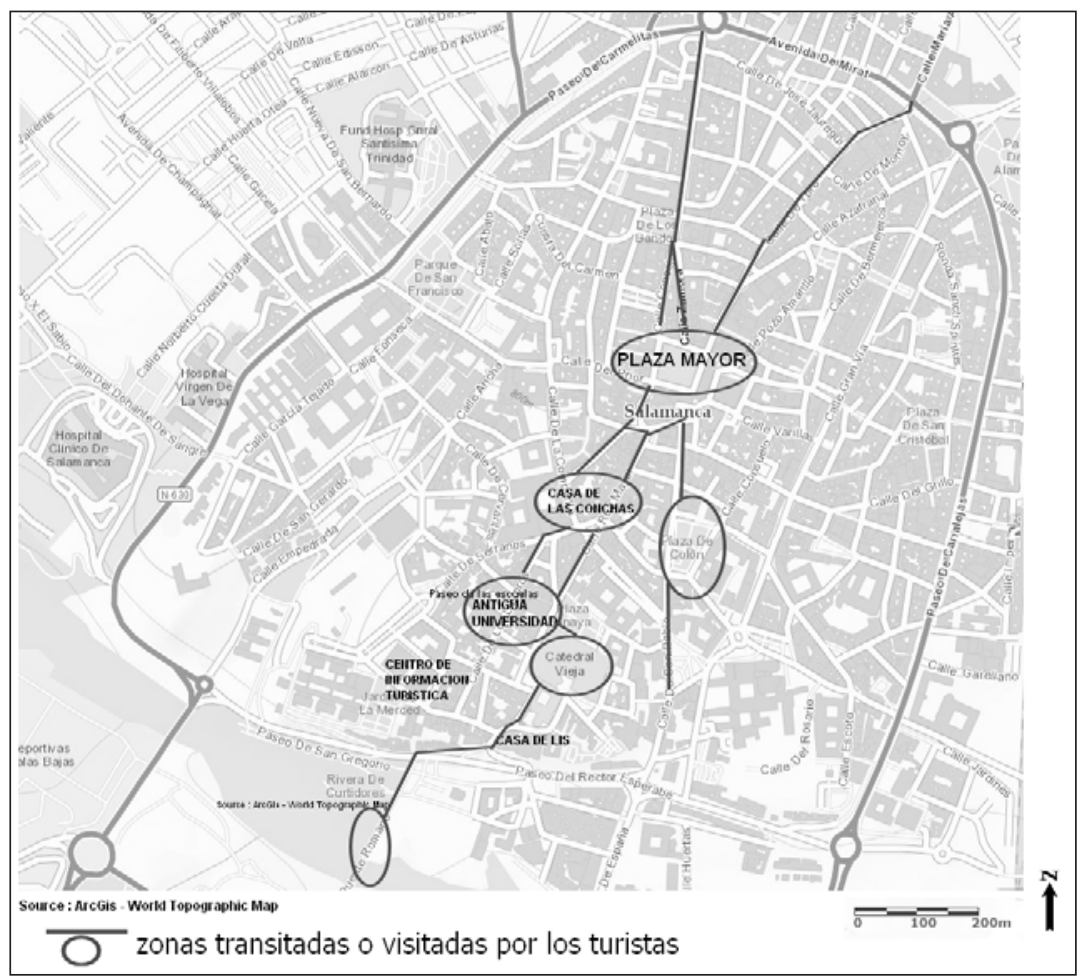

Fuente: elaboración propia a partir del cuestionario a turistas.

Solamente en estancias de mayor duración, por encima de una semana (y que, probablemente, tienen que ver más con visitas a familiares durante períodos vacacionales y con la consiguiente posibilidad de manejar información más detallada sobre otros puntos de interés), se aprecia una extensión palpable de las calles y lugares visitados por los turistas (figura 8). Esta extensión sigue una lógica orgánica al articularse en forma de apéndices arraigados en el eje central, una disposición semejante a la percepción ahormada por las visitas guiadas (figura 3). Al Norte de la Plaza, los entrevistados mencionan nuevos lugares como la Plaza de Los Bandos y la iglesia de San Marcos, en la calle de Zamora, que anteriormente pasaban inadvertidos. Al Oeste, reaparece el Palacio de Monterrey y, al Sur, la Casa Lis. Por último, el Convento de San Esteban, también recuperado, emerge como colofón de la calle San Pablo y punto de confluencia con la Gran Vía, abierta en la década de 1950 y dotada de un cierto carácter monumental derivado de su morfología (se emplea la arenisca de Villamayor como elemento de unidad y continuidad con el casco histórico tradicional), su funcionalidad (alberga diversas sedes administrativas) y su diseño (con arcadas que propician el paseo y aíslan al caminante del ruido de su denso tráfico). Conviene recalcar, con todo, que en 
los distintos subgrupos mencionados se repite el fenómeno de las citas a los monumentos y edificios singulares, mientras las calles que los comunican pasan desapercibidas como elementos que dan sentido y continuidad al espacio urbano de Salamanca.

\section{Cuadro 6}

RELACIÓN ENTRE LA DURACIÓN DEL VIAJE Y EL PROCEDIMIENTO DE ELECCIÓN DEL ITINERARIO

\begin{tabular}{|l|c|c|c|c|c|}
\hline Fuente de información & $\begin{array}{c}\text { Un } \\
\text { día }\end{array}$ & $\begin{array}{c}\text { Uno-tres } \\
\text { días }\end{array}$ & $\begin{array}{c}\text { Cuatro- } \\
\text { siete días }\end{array}$ & $\begin{array}{c}\text { Más de } \\
\text { siete días }\end{array}$ & Total \\
\hline Oficina de Turismo & 2 & 8 & 1 & - & 11 \\
\hline Visita guiada & 4 & 3 & 2 & 5 & 14 \\
\hline He comprado una guía turística & 3 & 1 & - & - & 4 \\
\hline Información de agencia de viajes & 2 & - & - & - & 2 \\
\hline Internet & - & 3 & - & - & 3 \\
\hline Familia & - & - & 4 & - & 4 \\
\hline Ya conocía Salamanca & 1 & 4 & - & 4 & 9 \\
\hline Camino sin itinerario prefijado & 4 & 4 & 1 & 2 & 11 \\
\hline Visitantes por intervalo de tiempo & 15 & 22 & 6 & 5 & 58 \\
\hline
\end{tabular}

Fuente: elaboración propia a partir del cuestionario a turistas.

El cuadro 6 ratifica algunas apreciaciones de este análisis de los planos mentales. En líneas generales, se advierte que una relación inversa entre duración de la estancia y diversidad de las fuentes de información consultadas, porque quienes permanecen cuatro ó más días recurren más al paseo libre y/o con frecuencia conocían la ciudad de antemano. De forma más concreta, hay que subrayar que la información de la Oficina de Turismo, tanto sus recomendaciones como sus planos, ejerce una influencia mayor en los visitantes que efectúan estancias más breves, lo que explicaría la concentración de sus desplazamientos en el eje central. En cambio, los guías turísticos son la referencia principal para los excursionistas y para quienes efectúan estancias largas, cuyos planos respectivos (figuras 5 y 8) coinciden en mencionar el Palacio de Monterrey, la Casa Lis y el Convento de San Esteban como destinos más allá del área central más conocida. Solamente se aparta de la tendencia general la asistencia de los viajeros de mayor duración a alguna visita guiada, que quizá se produzca al comienzo de su estancia como vía para formarse una idea global de la ciudad antes de profundizar en ciertos aspectos de su interés particular.

Una última cuestión derivada de la duración de la estancia y de las consiguientes variaciones en la percepción y utilización de la ciudad es la desigual frecuentación de establecimientos comerciales y hosteleros por parte de los turistas, una cuestión sin duda relevante para autoridades y empresarios locales. Los datos disponibles son muy claros a este respecto y han sido resaltados ya en otros trabajos sobre las prácticas de los turistas en la ciudad histórica (García y De la Calle, 2008). Los excursionistas se limitan a adquirir recuerdos $(37 \%)$ y reponer fuerzas en bares y restaurantes $(44 \%)$, siendo escasos quienes 
efectúan compras de alimentos o ropa. En cambio, las personas que permanecen en la ciudad más de tres días diversifican su tiempo y sus gastos y, además de los recuerdos y la hostelería, frecuentan tiendas de alimentación y de ropa diversa en proporciones superiores al 25 ó 30\%. En todo caso, y según se desprende de los planos aportados en este epígrafe, son los establecimientos de las calles aledañas a la Plaza Mayor los beneficiarios casi exclusivos del gasto efectuado por los turistas que visitan Salamanca.

\section{Figura 8 \\ PLANO SINTÉTICO DE LOS LUGARES VISITADOS POR LOS TURISTAS QUE PERMANECEN EN SALAMANCA DURANTE MÁS DE UNA SEMANA}

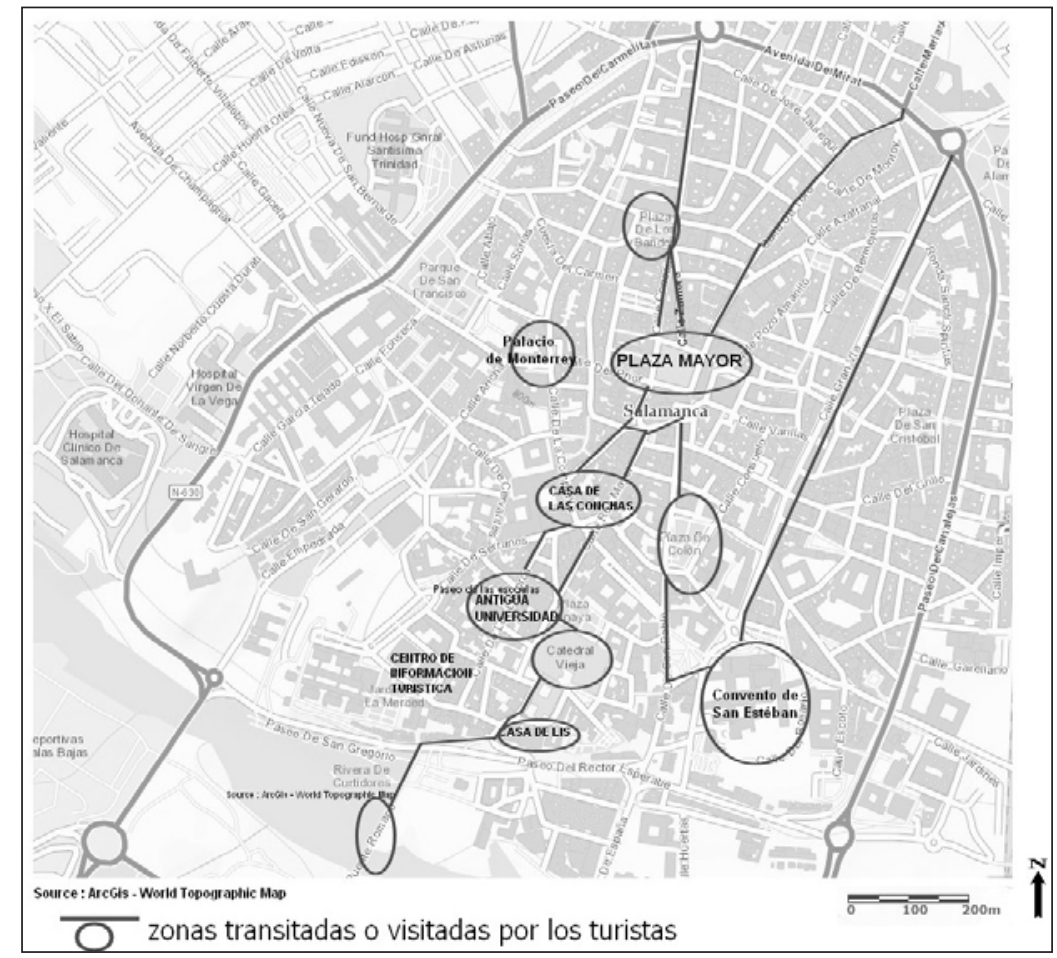

Fuente: elaboración propia a partir del cuestionario a turistas.

\subsection{Discusión de los resultados}

De los epígrafes precedentes se desprende, como resultado principal, que los visitantes, independientemente de la modalidad de su viaje, siguen unos itinerarios muy limitados y visitan un restringido abanico de monumentos: el eje Plaza Mayor-Rúa Mayor-Catedrales/ Universidad conforma el distrito o recinto turístico de Salamanca. Otros muchos monumentos sumamente próximos a este recinto quedan al margen de este flujo de turistas y viajeros cuyas características personales particulares, como constatan otros trabajos 
(Marrero y Abdul-Jalbar, 2012), parecen ejercer una influencia muy tenue sobre su manera efectiva de reconocer la ciudad, que se ajusta a un patrón común muy marcado por la información adquirida antes o durante la estancia. Ya en el año 2002, preguntados los visitantes de Salamanca por los lugares que habían visitado o tenían intención de visitar, las Catedrales fueron citadas por el $97,8 \%$ del total, la fachada de la Universidad y el patio de las Escuelas Menores por el 95,2\%, la Clerecía y la Universidad Pontificia — frente a la Casa de las Conchas - por el 89,5\%, mientras otros destinos algo periféricos a este núcleo central como el convento de San Esteban, la Casa Lis y la Hospedería de Fonseca fueron mencionados por el 73,5\%, el 54,6\% y el 55,3\% de los encuestados (García y De la Calle, 2008, p. 54). El patrón de desplazamiento no sólo es acusado, sino además persistente en el tiempo, lo que requiere una acción explícita y decidida de los gestores turísticos para extender los límites del distrito turístico de la ciudad.

La duración de la estancia del turista no modifica en lo fundamental este patrón fundamental, aunque lo extiende hacia el norte y el sur a lo largo de las calles que convergen en la Plaza Mayor y que actúan como vectores de la limitada difusión del tránsito turístico por el centro de Salamanca. La información proporcionada por familiares y amigos residentes en la ciudad, o la propia experiencia adquirida en visitas previas, son dos fuerzas centrífugas que animan a los turistas a alejarse un poco del distrito central y contemplar otros monumentos.

\section{Figura 9 \\ PLANO TURÍSTICO DE SALAMANCA}

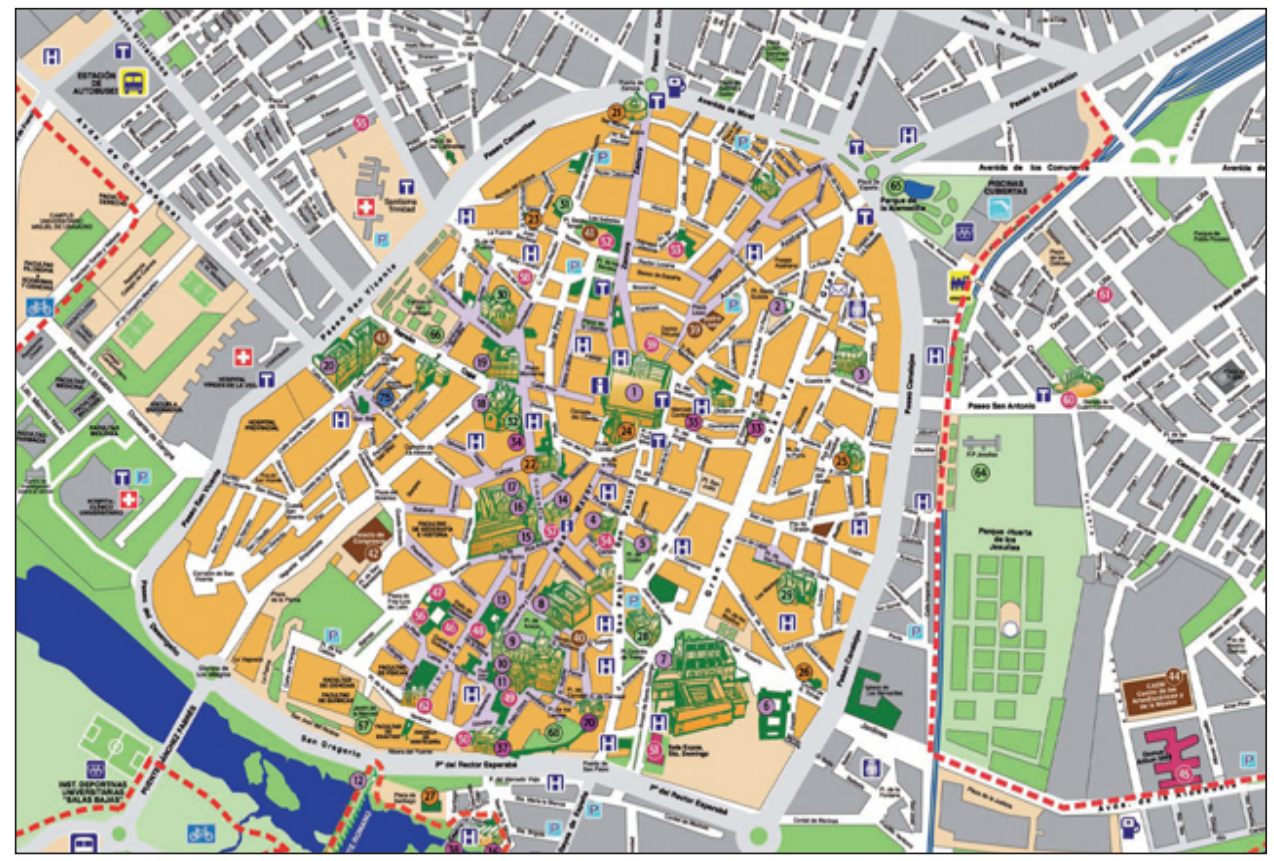

Fuente: Oficina de Turismo de Salamanca. http://www.salamanca.es/es/servicios/oficina-de-turismo-on-line/plano 
Pero el poder de las fuerzas centrípetas es mucho mayor y procede de dos fuentes principales: la Oficina de Turismo (con su documentación y sus consejos verbales) y los guías turísticos (con sus itinerarios preestablecidos). En línea con los resultados de investigaciones de ámbito nacional (Luna, 2012), la Oficina de Turismo modela de forma decisiva la imagen de la ciudad y, con ella, las visitas de los turistas cuando recomienda solamente, para estancias de un día, el recorrido por el distrito central; en los planos que proporciona (figura 9) resalta o representa ese mismo recinto sin fomentar la curiosidad del turista por otros lugares un poco más apartados.

Los guías también producen su propia ciudad para el turista, pero se trata de una ciudad definida por la necesidad de optimizar la relación entre el número de monumentos mostrados y la duración de la visita a pie. De ahí las pequeñas, pero apreciables diferencias entre los planos mentales dibujados por los turistas guiados y por los turistas independientes, así como la paradójica semejanza entre el plano de los primeros y el de quienes permanecen más de una semana en la ciudad y dedican algún tiempo a una de estas visitas. La elección concreta de esos destinos inmediatos al distrito central, pero no pertenecientes al mismo sensu stricto, obedece tanto a su interés intrínseco como a la necesidad de amenizar la visita con referencias a personajes conocidos entre el gran público. Según los datos de las entrevistas y la observación de campo, pocos son los visitantes particulares que se acercan al Palacio de Monterrey, a apenas cincuenta metros de la Plaza Mayor.

Estas fuerzas centrípetas que refuerzan a diario la producción del distrito central vienen a demostrar, una vez más, que ningún lugar tiene por sí mismo una vocación turística predeterminada. Los destinos turísticos más o menos masivos son producidos colectivamente para rentabilizar la proyección de demandas sociales (Battino, 2013) sobre ciertos espacios - naturales o, como en este caso de estudio, construidos - que pueden comercializarse con cierta facilidad entre un público numeroso que no reclama complejidad ni profundidad, sino más bien simplicidad y celeridad (Ashworth y Page, 2011). En aras de la simplicidad y la celeridad, pues, lugares del interés de la Hospedería de Fonseca, la Torre del Clavero, la Torre del Aire, la Torre de Abrantes, el Patio Chico, el Huerto de Calixto y Melibea, el Convento de las Dueñas, las iglesias de Sancti-Spiritus o Santo Tomás Cantuariense, o el Palacio de Congresos y Exposiciones de Castilla y León, entre otros, permanecen al margen de las rutas más frecuentadas. Más llamativa es la ausencia de menciones en los cuestionarios al Palacio de Anaya, frente a la Catedral Nueva, al Patio de Escuelas Mayores, que se abre ante la fachada de la Universidad, o al complejo de la Universidad Pontificia y la Iglesia de la Clerecía, frente a la Casa de Las Conchas: los visitantes han caminado ante ellos con toda seguridad, pues se ubican en el mismo recinto hipertransitado, pero esa combinación de simplicidad y celeridad que parece gobernar la estancia del turista medio en Salamanca termina por velar su recuerdo a la hora de responder los cuestionarios.

Desde esta perspectiva se comprende mucho mejor la reducción de las calles a la mera condición de conectores de monumentos. El afán por contemplar fachadas monumentales bien conocidas, que permitan al visitante regresar a su hogar convencido de haber «visto todo», transforma las calles en túneles por los que se transita para enlazar un monumento con el siguiente, sin manifestar interés por la sucesión de edificaciones y usos de diverso tipo y funcionalidad que componen una calle. En el caso de los cascos patrimoniales, 
como el de Salamanca, este fenómeno resulta particularmente lamentable porque priva al monumento de su sentido verdadero como pieza de un tejido urbano más extenso. La realidad orgánica de la ciudad histórica es sustituida por una visión más icónica o temática (Millán y Fernández, 2014) articulada en torno a unos jalones tan grandiosos como escasos y tan impactantes como descontextualizados. Naturalmente, las calles que no conducen a elementos singulares bien destacados en los planos y guías se ignoran de forma sistemática (como se ha constatado también en el caso de Gerona) y el visitante carece, al final, de una aproximación directa a la vida real y cotidiana de la ciudad histórica.

La víctima más paradójica de todo este proceso de simplificación de la ciudad histórica de Salamanca es el Centro de Información Turística Monumenta Salmanticae. Ubicado en la antigua iglesia de San Millán y concebido para ejercer como punto de recepción de visitantes y centro de interpretación del patrimonio de la ciudad (mediante maquetas, fotografías, recreaciones virtuales y material audiovisual) se publicita en Internet como «lugar ideal para comenzar tu visita a la ciudad». No obstante, resulta completamente desconocido para los visitantes entrevistados porque se sitúa al sur del casco antiguo, ya fuera de lo que hemos delimitado aquí como distrito turístico central (ver figuras precedentes),en una calle apenas transitada y, sorprendentemente, durante el trabajo de campo no se ha encontrado ningún cartel indicador que conduzca hasta este lugar. Por tanto, se aprecia una cierta contradicción entre las diferentes medidas e instrumentos de promoción turística que se adoptan desde el Ayuntamiento de Salamanca, toda vez que la Oficina de Turismo, situada en la Plaza Mayor, debería recomendar una visita a Monumenta Salmanticae como paso previo para el posterior paseo por la ciudad.

\section{HACIA UNA MOVILIDAD TURÍSTICA MÁS COMPRENSIVA EN LA CIUDAD HISTÓRICA DE SALAMANCA}

Existe, por lo tanto, cierto margen para la aplicación de medidas orientadas a ampliar la red de lugares visitados y de calles transitadas por los turistas que llegan a Salamanca y que, en caso de salir del recinto turístico, disfrutarían de una experiencia mucho más rica y diversa de la ciudad. Se pueden proponer acciones relativas a la señalización fija y otras referidas a la información verbal y escrita que se proporciona a los turistas. En este punto, pues, se parte de la convicción de que las autoridades locales sí pueden influir, hasta cierto punto al menos, en el uso que los turistas hacen de la ciudad, frente a la postura contraria defendida por Ashworth y Page (2011).

En lo referido a la señalización, el cuadro 5 detectaba que un porcentaje importante de turistas la considera mejorable, sobre todo entre quienes viajan por su cuenta. El Ayuntamiento de Salamanca parece tener conciencia de estas deficiencias y viene renovando la señalización desde finales de 2014, con un presupuesto aprobado de 447.000 euros. Con el objetivo de fondo de prolongar la estancia media de los turistas, el plan de señalización menciona explícitamente la necesidad de orientar el flujo de turistas hacia puntos menos conocidos y de facilitar el tránsito hacia tales lugares, al objeto de evitar la congestión que padece el recinto central en momentos álgidos como los puentes festivos (del Pilar, de Todos los Santos, de la Constitución, del primero de Mayo...), donde se registran picos de afluencia de visitantes de manera sistemática y reiterada. 
A tal efecto, está previsto colocar mástiles con módulos de tres tipos: direccionales (para orientar al visitante), patrimoniales (para señalizar rutas y recorridos) e informativos (con datos sobre los monumentos y la ciudad). También se colocarán placas en el suelo frente a los monumentos más característicos, a fin de añadir información sin afectar al paisaje urbano. Ahora bien, falta por comprobar si por «puntos menos conocidos» se refiere solamente a más monumentos o se va a extender la consideración de destinos promocionables a las calles comerciales, a las riberas del río Tormes o a los parques que bordean el casco histórico (Alamedilla, Campo de San Francisco, Huerta de los Jesuitas), por ejemplo. Tampoco queda claro si se van a señalizar itinerarios conducentes a subconjuntos de interés exteriores a la antigua ronda amurallada (caso del barrio del Oeste, donde se acumulan iniciativas ciudadanas y artísticas de regeneración urbana muy meritorias desde hace unos pocos años) o simplemente se va a mejorar la información que se ofrece sobre los edificios singulares en paneles diseñados con ese fin.

Respecto a la información que se distribuye a los turistas, es preciso replantear algunos aspectos, una vez que el propio Consistorio ha tomado conciencia de la necesidad de diversificar los destinos e itinerarios. Algunas sugerencias en este sentido son:

- La confección de planos con rutas o itinerarios temáticos bien diferenciados: Salamanca conventual, Salamanca de los palacios, Salamanca universitaria, Salamanca de los jardines, Salamanca de las callejas y plazuelas... a fin de cubrir demandas o intereses específicos de grupos determinados de visitantes. Como se ha hecho en otras ciudades históricas, estos itinerarios temáticos podrían balizarse sobre el terreno con indicaciones en el pavimento, a fin de guiar mejor a los turistas sin afectación visual de los edificios protegidos. La página web de Turismo de Salamanca (Turismo de Salamanca <en línea>) ya sugiere algunas rutas de este tipo (Salamanca Jacobea, Huellas de Santa Teresa, Salamanca-Iberoamérica, Salamanca Patrimonio de la Humanidad), pero los datos mostrados en este artículo sugieren que no se siguen estas recomendaciones y las visitas están demasiado condicionadas por la concentración del flujo de paseantes en el recinto principal.

- Desde la Oficina de Turismo debería recomendarse una primera aproximación a los recursos de la ciudad en Monumenta Salmanticae, para que el visitante particular seleccione después su propio itinerario sin verse tan condicionado por las indicaciones del personal de dicha Oficina.

- La incorporación explícita del turismo comercial como destino, señalizando claramente las zonas de mayor concentración de establecimientos; la relación entre duración de la estancia y frecuentación de comercios ha quedado muy clara en los cuestionarios, luego parece necesario orientar un poco a quienes tienen interés en este tipo de ocio. La señalización en las calles comerciales debería acompañar en idéntico sentido, como suele hacerse en los llamados centros comerciales abiertos (Elizagárate y Zorrilla, 2004; Bratos y Gaete, 2012).

- La oferta de visitas guiadas gratuitas organizadas por residentes en la ciudad que se ofrecen voluntarios para compartir sus lugares preferidos con los visitantes. Se trata de una modalidad cada vez más extendida de actividad que, además, genera 
ingresos en establecimientos comerciales y hosteleros ubicados en localizaciones alternativas al distrito central y muestra al visitante realidades que a menudo pasan desapercibidas en la información oficial.

\section{Figura 10 \\ PROPUESTA DE PLANO BÁSICO DE LOS RECURSOS TURÍSTICOS DEL CASCO HISTÓRICO DE SALAMANCA}

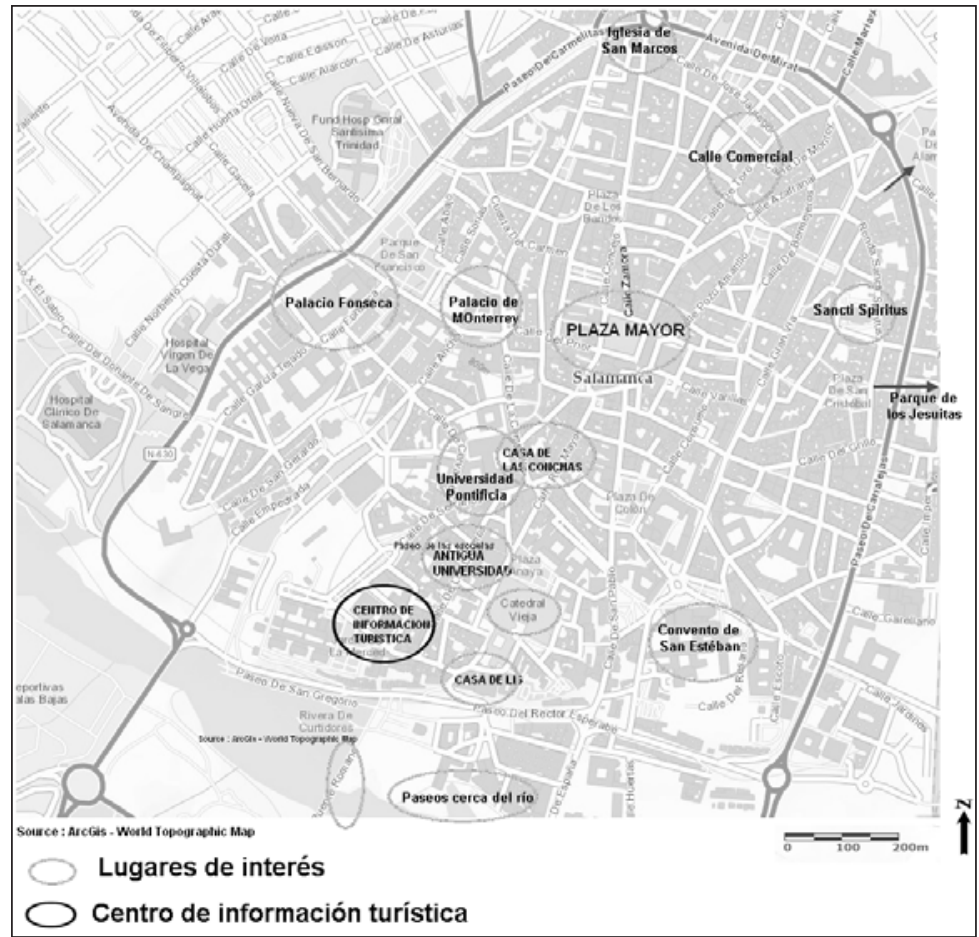

Fuente: elaboración propia.

La figura 10 muestra cómo podría plantearse un plano de la Salamanca histórica que resaltase una variedad de recursos y destinos más amplia que la recogida en las figuras 3 a 9. En esta propuesta, el centro de interpretación Monumenta Salmanticae adquiere un papel protagonista, tanto informativo como perceptivo. Informativo porque, como se acaba de sugerir, proporciona al visitante una visión amplia de los destinos de la ciudad. Y perceptivo porque su ubicación céntrica, pero externa al recinto principal actual, formaría en el visitante, ya de entrada, una imagen diferente del casco patrimonial de Salamanca, muchos menos mediatizada por el eje Plaza Mayor-Catedrales-Universidad. La presencia destacada de lugares de interés en la periferia del casco, como la Hospedería de Fonseca, la iglesia de San Marcos, las riberas del Tormes o la iglesia de Sancti-Spíritus - entre otros que no se cartografían para simplificar la imagen - pretende propiciar los recorridos de los visitantes por calles de la ciudad más alejadas del distrito central 
y sus aledaños. Así se enriquecería la experiencia del turista con destinos adicionales que, además, no se reducen a las fachadas y los monumentos, sino que incorporan otros elementos del tejido urbano y social de la ciudad.

\section{BIBLIOGRAFÍA}

ASHWORTH, G.J. (2000): «Heritage, tourism and places: a review». Tourism Recreation Research vol. 25, pp. 19-29.

ASHWORTH, G.J. y PAGE, S.J. (2011): «Urban tourism research: Recent progress and current paradoxes». Tourism Management vol. 32, pp. 1-15.

ASHWORTH, G.J., y TUNBRIDGE, J. E. (2000): The tourist-historic city: retrospect and prospect of managing the heritage city. Londres, Belhaven.

BATTINO, S. (2013): «La imagen que perciben los turistas que visitan Cerdeña. Primeras consideraciones extraídas de una investigación realizada mediante cuestionarios». Cuadernos de Turismo $\mathrm{n}^{\mathrm{O}}$ 32, pp. 37-64.

BERNADÓ, O., BIGORRA, A., PÉREZ, Y., RUSSO, A. P., y ANTON CLAVÉ, S. (2012): «Analysis of tourist behavior based on tracking data collected by GPS». EN Díaz, L., Granell, C. y Huerta , J. Eds. Discovery of Geospatial Resources: Methodologies, Technologies, and Emergent Applications. Pennsylvania, IGI Global, pp. 241-260.

BRATOS MARTÍN, M. y GAETE QUEZADA, R. (2012): «Los centros comerciales abiertos en España: una mirada desde el concepto de responsabilidad social corporativa». Distribución y Consumo $\mathrm{n}^{\circ} 124$, pp. 1-13.

CÓCOLA GANT, A. (2011): «El Barrio Gótico de Barcelona. De símbolo nacional a parque temático». Scripta Nova. Revista Electrónica de Geografía y Ciencias Sociales vol. XV, no 371.

DE LA CALLE VAQUERO, M. y GARCÍA HERNÁNDEZ, M. (1998a): «Ciudades históricas: patrimonio cultural y recurso turístico». Ería. Revista Cuatrimestral de Geografía, no 47, pp. 249-266.

DE LA CALLE VAQUERO, J.A. y GARCÍA HERNÁNDEZ, M. (1998b): «Fuentes y técnicas para el estudio del turismo en las ciudades históricas». Ería. Revista Cuatrimestral de Geografía, no 47, pp. 326-333.

DE LAS RIVAS SANZ, J. y VÁZQUEZ JUSTEL, G. (2011): «El paisaje urbano histórico de la «ciudad vieja» de Salamanca, claves para un plan de gestión». Ciudades, $n^{\circ} 14$, pp. 57-80.

DONAIRE BENITO, J.A. y GALÍ ESPERT, N. (2003): «La imagen «a priori» de los destinos turísticos monumentales: el caso de Girona». Papers de Turisme, $\mathrm{n}^{\circ} 34$, pp. 78-97.

DONAIRE BENITO, J.A. y GALÍ ESPERT, N. (2008): «Modeling tourist itineraries in heritage cities. Routes around the Old District of Girona». Pasos. Revista de Turismo y Patrimonio Cultural vol. 6, no 3, pp. 435-449.

DONAIRE BENITO, J.A. y GALÍ ESPERT, N. (2011): «La imagen turística de Barcelona en la comunidad de Flickr». Cuadernos de Turismo, n 27, pp. 291-303.

EDWARDS, D., GRIFFIN, T. y HAYLLAR, B. (2008): «Urban tourism research: developing and agenda». Annals of Tourism Research, vol. 35, pp. 1032-1052. 
ELIZAGÁRATE, V. de y ZORRILLA, P. (2004): «El comercio urbano como factor estratégico para la competitividad entre ciudades. Gipuzkoa: un caso de centro comercial abierto en red». Distribución y Consumo, $\mathrm{n}^{\circ}$ 78, pp. 101-113.

ESCUDERO GÓMEZ, L.A. (2013): «La imagen urbana de Santiago de Compostela (España). Un estudio de su representación pública, mediática, promocional y artística». Boletín de la Asociación de Geógrafos Españoles, nº 62, pp. 265-294.

GALÍ ESPELT, N. (2009): «Propuesta metodológica para el análisis del comportamiento de la demanda de turismo cultural a partir del diseño de un grafo valorizado. El ejemplo de Girona». Revista de Análisis Turístico, n ${ }^{\circ}$, pp. 39-48.

GALÍ ESPELT, N. y DONAIRE BENITO, J.A. (2006): «La imagen percibida por los turistas de la ciudad de Girona». Estudios Turísticos, n 168, pp. 123-139.

GARCÍA HERNÁNDEZ, M. y DE LA CALLE VAQUERO, M. (2008): «Los síntomas: el comportamiento del visitante. ¿Qué está pasando? Reflexiones sobre los modos de consumo turístico del patrimonio urbano. Una aproximación desde la geografía». En Rico, J.C. Coord. Cómo enseñar el objeto cultural. Madrid, Sílex, pp. 35-95.

GARCÍA HERNÁNDEZ, M. y DE LA CALLE VAQUERO, M. (2013): «Capacidad de carga turística y gestión de flujos de visitantes en espacios patrimoniales de dominante histórico-cultural». En Melgosa Arcos, F.J. coord. Turismos de interior: planificación, comercialización y experiencias. Madrid, Pirámide, pp. 380-406.

GARCÍA ZARZA, E. (2002): «El turismo cultural en Castilla y León. El caso singular de Las Edades del Hombre». Cuadernos de Turismo, n 10, pp. 23-67.

HERNÁNDEZ SÁNCHEZ, A.I. (2010): «Del atractivo al posicionamiento. Los retos del destino turístico Salamanca», en Soluciones sostenibles para las Ciudades Patrimonio Mundial, Valladolid, Fundación del Patrimonio Histórico de Castilla y León, pp. 95-116.

HERRERO PRIETO, L.C. y otros (2006): «The economic impact of cultural events. A case-study of Salamanca 2002, European Capital of Culture». European Urban and Regional Studies, vol. 13, pp. 41-57.

JIMÉNEZ SÁNCHEZ, G., FERNÁNDEZ CUADRADO, O. (2013): «Las Edades del Hombre: pasado, presente y futuro». En Melgosa Arcos, F.J. Coord. Turismos de interior: planificación, comercialización y experiencias. Madrid, Pirámide, pp. 341-365.

JUDD, D.R. (2003): «Visitors and the spatial ecology of the city», en Hoffmann, L.M., Fainstein, S.S. y Judd, D.R. Eds. Cities and visitors. Regulating people, markets, and city space. Oxford, Blackwell Publishing, pp. 23-38.

LADWEIN, R. (2003): «Les modalités de l'appropriation de l'expérience de consommation: le cas du tourisme urbain». En Sociétés, consommations et consommateurs. París, L'Harmattan, pp. 85-98.

LUNA CORTÉS, G. (2012): «Las fuentes de información empleadas por los turistas vacacionales en los destinos turísticos». Investigaciones Turísticas, n ${ }^{\circ} 4$, pp. 132-139.

LLORENTE PINTO, J.M. (2004): «Relaciones internacionales hoy», en Historia de la Universidad de Salamanca, Vol. 3, Tomo 2 (Saberes y Confluencias). Salamanca, Universidad de Salamanca, pp. 1.377-1.397.

MARRERO RODRÍGUEZ, J.R. y ABDUL-JALBAR, B. (2012): «Turismo cultural y planificación del viaje: un caso de estudio». Tourism \& Management Studies nº 8, pp. 41-47. 
MILLÁN MILLÁN, P. y FERNÁNDEZ, L. (2014): «Aproximación al estudio de los procesos de transformación en las ciudades históricas. La tematización». EURE, ${ }^{\circ}$ 120, pp. 201-219.

PARDO ABAD, C.J. (2011): «El turismo idiomático en España como potenciador cultural en ciudades patrimoniales: el caso de Salamanca y Alcalá de Henares». Cuadernos de Turismo, $\mathrm{n}^{\circ} 27$, pp. 701-723.

PEARCE, D.G. (2001): «An integrative framework for urban tourism research». Annals of Tourism Research, vol. 28, pp. 926-946.

SHOVAL, N. e ISAACSON, M. (2007): Tracking tourists in the digital age. Annals of Tourism Research, vol. 34, pp. 141-159.

TROITIÑO VINUESA, M.A. y TROITIÑO TORRALBA, L. (2009): «Turismo y patrimonio en Castilla y León: las ciudades Patrimonio de la Humanidad (Ávila, Salamanca y Segovia) como destinos turísticos de referencia». Polígonos, no 19, pp. 145-178.

TROITIÑO VINUESA, M.A. y otros (1998): «Toledo: problemática e implicaciones urbanas del turismo». Ería. Revista Cuatrimestral de Geografía, no 47, pp. 299-325.

UNESCO (1988): Convention concerning the protection of the world cultural and natural heritage. Twelfth session. World Heritage Committee. Brasilia. <http://whc.unesco.org/ archive/1988/sc-88-conf001-8e.pdf>

YEUNG, H.W.CH. (2003): «Practicing new economic geographies: a methodological examination». Annals of the Association of American Geographers, vol. 93, pp. 442-462.

\section{RECURSOS EN INTERNET}

Las Edades del Hombre

$<$ http://www.lasedades.es/index.php?option=com_content\&view=article\&id=73\&Ite $\operatorname{mid}=112>$

Monumenta Salmanticae

$<$ http://www.fundacionpatrimoniocyl.es/textosARQ.asp?id=538>

Museo del Prado

$<$ https://www.museodelprado.es/enciclopedia/enciclopedia-on-line/voz/velazquez/>

Turismo de Salamanca

$<$ http://www.salamanca.es/es/>

UNESCO World Heritage List

Old City of Salamanca - <http://whc.unesco.org/en/list/381>

(todos consultados por última vez el 28 de septiembre de 2015) 
